\title{
Recent progress of 2D metalorganic frameworks and their derivatives for oxygen evolution electrocatalysis
}

Huang, Wei; Tang, Jing; Diao, Fangyuan; Engelbrekt, Christian; Ulstrup, Jens; Xiao, Xinxin; Mølhave, Kristian

Published in:

ChemElectroChem

Link to article, DOI:

10.1002/celc.202001137

Publication date:

2020

Document Version

Peer reviewed version

Link back to DTU Orbit

Citation (APA):

Huang, W., Tang, J., Diao, F., Engelbrekt, C., Ulstrup, J., Xiao, X., \& Mølhave, K. (2020). Recent progress of 2D metalorganic frameworks and their derivatives for oxygen evolution electrocatalysis. ChemElectroChem, 7(23), 4695-4712. https://doi.org/10.1002/celc.202001137

\section{General rights}

Copyright and moral rights for the publications made accessible in the public portal are retained by the authors and/or other copyright owners and it is a condition of accessing publications that users recognise and abide by the legal requirements associated with these rights.

- Users may download and print one copy of any publication from the public portal for the purpose of private study or research.

- You may not further distribute the material or use it for any profit-making activity or commercial gain

- You may freely distribute the URL identifying the publication in the public portal 


\section{ChemElectroChem}

\section{Fhemistry Europe}

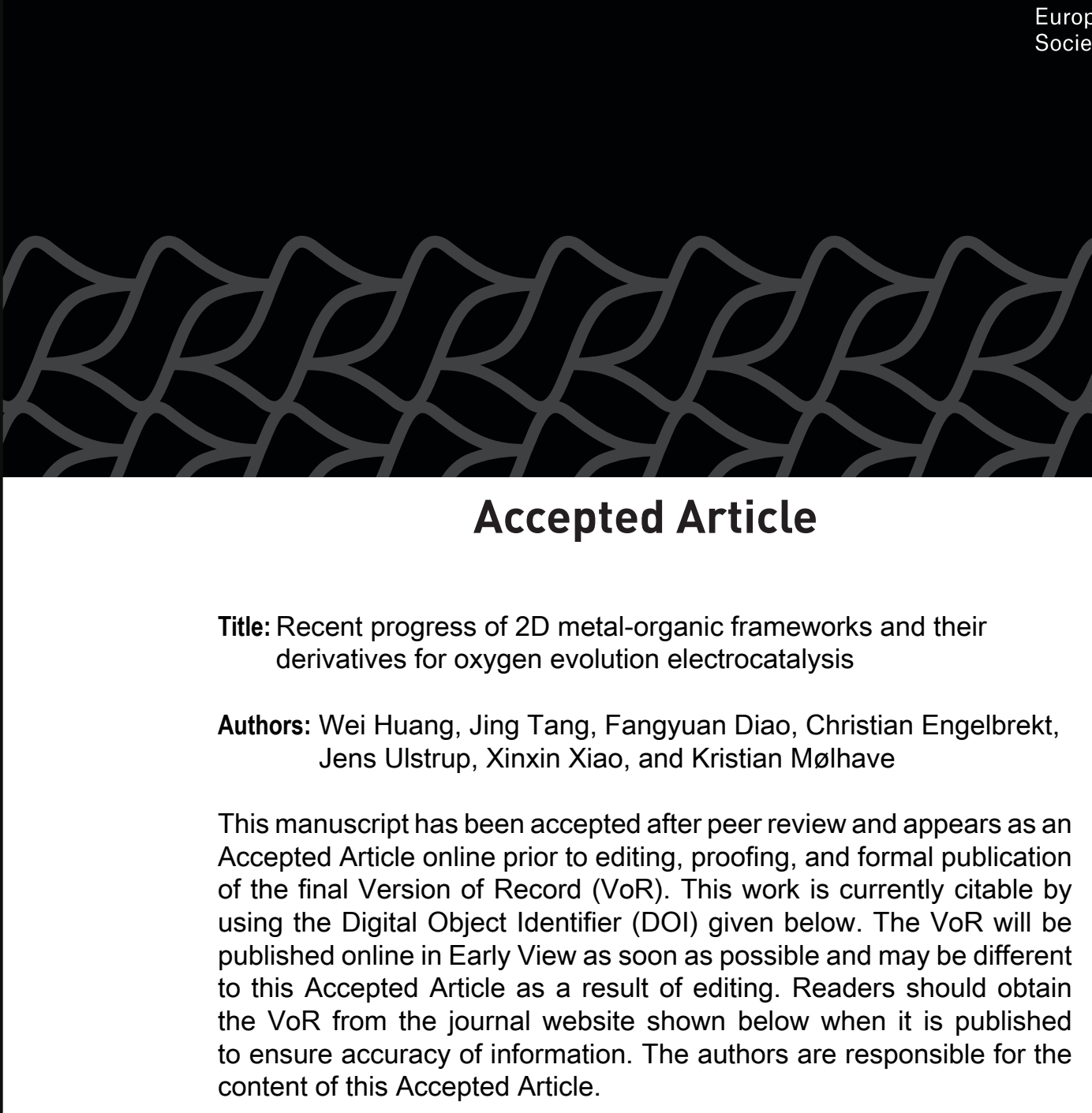

To be cited as: ChemElectroChem 10.1002/celc.202001137

Link to VoR: https://doi.org/10.1002/celc.202001137 


\section{derivatives for oxygen evolution electrocatalysis}

Wei Huang ${ }^{a, c}$, Jing Tang ${ }^{a}$, Fangyuan Diao ${ }^{a}$, Christian Engelbrekt ${ }^{a}$, Jens Ulstrup ${ }^{a, b}$, Xinxin Xiao ${ }^{a *}$ and Kristian Mølhave ${ }^{c^{*}}$

${ }^{a}$ Department of Chemistry, Technical University of Denmark, DK-2800 Kongens Lyngby, Denmark.

${ }^{\mathrm{b}}$ Kazan National Research Technological University, K. Marx Str., 68, 420015 Kazan, Republic of Tatarstan, Russian Federation.

${ }^{c}$ DTU Nanolab - National Center for Nanofabrication and Characterization, Technical University of Denmark, DK-2800 Kongens Lyngby, Denmark.

Corresponding authors: Xinxin Xiao (xixiao@kemi.dtu.dk); Kristian Mølhave (krmo@dtu.dk).

Abstract: The development of high-performance transition metal-based electrocatalysts for the oxygen evolution reaction (OER) is paramount for electrochemical secondary metal-air batteries and water splitting. Two-dimensional (2D) metal-organic framework (MOF) nanosheets have recently emerged as a novel class of efficient electrocatalysts for the OER due to a high specific surface area, ultrasmall thickness and abundance of active sites. Here, we summarize recent progress in the preparation and characterization of 2D transition metal-based MOFs (e.g. Ni, Co and $\mathrm{Cu}$ ), as well as their composites and derivatives, including metals/alloys, metal oxides/chalcogenides and metal phosphides/hydroxides, as OER electrocatalysts reported over the past several years. Design principles and preparation routes are presented. The performance of the electrocatalysts is directly compared in terms of $\eta$ (thermodynamics) and electrocatalytic current density (kinetics), as well as operational stability (economics). Many of these materials exhibit superior catalytic activity compared to the noble-metal based catalysts such as $\mathrm{RuO}_{2}(\eta<$ $300 \mathrm{mV}$ at $10 \mathrm{~mA} \mathrm{~cm}{ }^{-2}$ ), and considerable stability with negligible decay with operation over several hours to days. Challenges and perspectives of applying 2D MOFs and their derivatives for OER electrocatalysis are also discussed.

Keywords: 2D MOF; MOF derivatives; oxygen evolution reaction; electrocatalysis. 


\section{Contents}

28

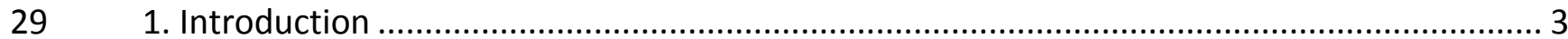

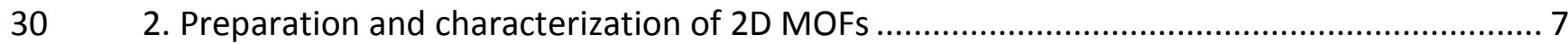

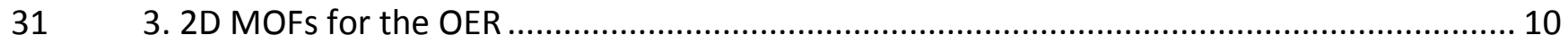

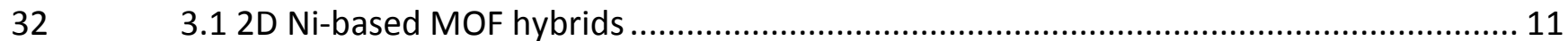

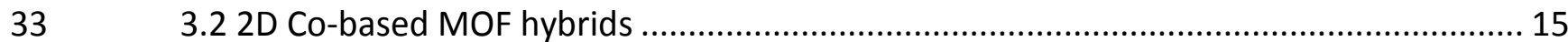

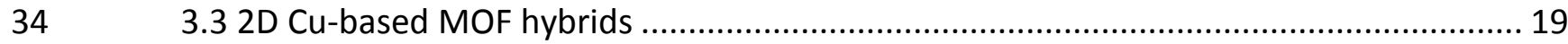

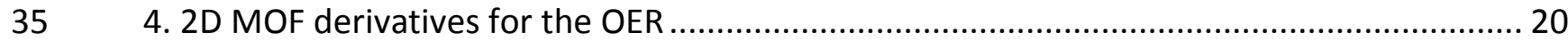

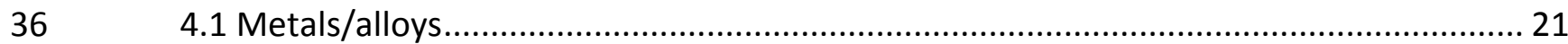

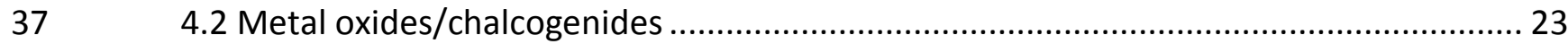

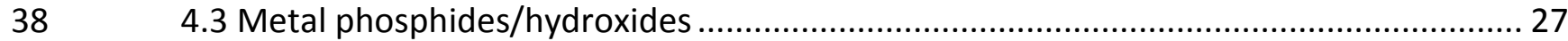

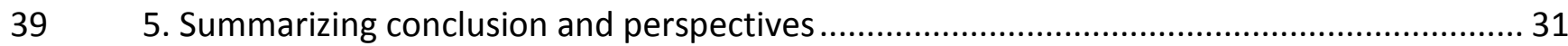

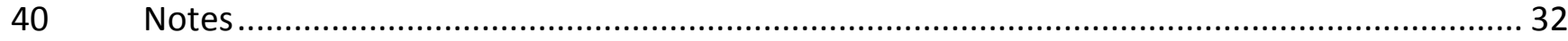

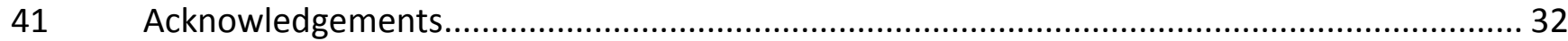

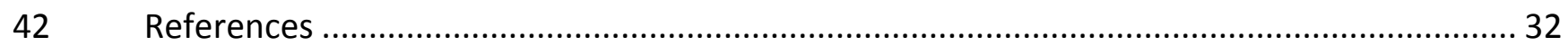

43

44

45

46

47

48

49 


\section{1. Introduction}

51 Green energy technologies are urgently needed due to forthcoming insecurity of fossil fuel supply,

52 increasing global energy demand and critical environmental concerns. ${ }^{[1-8]}$ Rechargeable metal-

53 air batteries and electrochemical water splitting (Figure 1a) ${ }^{[9]}$ are promising systems for the

54 storage and conversion of renewable electricity, for example, from solar and wind energy. They

55 have attracted considerable attention due to their environmental friendliness, high efficiency,

56 and high safety. ${ }^{[10-13]}$ The electrochemical oxygen evolution reaction (OER) is a core process in

57 such devices, highlighting the importance of high-performance OER electrocatalysts.

58 The OER is the process in which $\mathrm{H}_{2} \mathrm{O}$ or $\mathrm{OH}^{-}$is oxidized to dioxygen gas at the anode of an

59 electrolyzer cell. Ideally, the process proceeds around the thermodynamic limit of $1.23 \mathrm{~V}$ versus 60 the reversible hydrogen electrode (RHE), but typically requires overpotentials of several 61 hundreds of millivolts. The OER mechanisms vary depending on $\mathrm{pH}$ of the electrolyte and catalyst

62 surface. ${ }^{[14,15]}$ The well-accepted OER model process includes four separate steps with overall

63 four-electron transfer in acidic (eq. 1) or alkaline (eq. 2) solution, respectively. X* indicates one 64 active site on the electrocatalyst surface, while $X^{*} \mathrm{OH}, X^{*} \mathrm{O}$ and $\mathrm{X}^{*} \mathrm{OOH}$ refer to different OER 65 intermediates absorbed on active sites during the OER (Figure $1 b){ }^{[14,16]}$

$66 \quad 2 \mathrm{H}_{2} \mathrm{O} \rightarrow \mathrm{O}_{2}+4 \mathrm{H}^{+}+4 \mathrm{e}^{-} \quad$ (acidic condition)

$67 \mathrm{H}_{2} \mathrm{O}+\mathrm{X}^{*} \rightarrow \mathrm{X}^{*} \mathrm{OH}+\mathrm{H}^{+}+\mathrm{e}^{-}$

$68 \quad \mathrm{X}^{*} \mathrm{OH} \rightarrow \mathrm{X}^{*} \mathrm{O}+\mathrm{H}^{+}+\mathrm{e}^{-}$

$69 \mathrm{H}_{2} \mathrm{O}+\mathrm{X}^{*} \mathrm{O} \rightarrow \mathrm{X}^{*} \mathrm{OOH}+\mathrm{H}^{+}+\mathrm{e}^{-}$

$70 \quad \mathrm{X}^{*} \mathrm{OOH} \rightarrow \mathrm{X}^{*}+\mathrm{O}_{2}+\mathrm{H}^{+}+\mathrm{e}^{-}$

$714 \mathrm{OH}^{-} \rightarrow 2 \mathrm{H}_{2} \mathrm{O}+\mathrm{O}_{2}+4 \mathrm{e}^{-} \quad$ (alkaline condition)

$72 \mathrm{OH}^{-}+\mathrm{X}^{*} \rightarrow \mathrm{X}^{*} \mathrm{OH}+\mathrm{e}^{-}$

$73 \mathrm{X}^{*} \mathrm{OH}+\mathrm{OH}^{-} \rightarrow \mathrm{X}^{*} \mathrm{O}+\mathrm{H}_{2} \mathrm{O}+\mathrm{e}^{-}$

$74 \quad \mathrm{X}^{*} \mathrm{O}+\mathrm{OH}^{-} \rightarrow \mathrm{X}^{*} \mathrm{OOH}+\mathrm{e}^{-}$

$75 \quad \mathrm{X}^{*} \mathrm{OOH}+\mathrm{OH}^{-} \rightarrow \mathrm{X}^{*}+\mathrm{O}_{2}+\mathrm{H}_{2} \mathrm{O}+\mathrm{e}^{-}$ 
76 The benchmark OER electrocatalysts are noble metal-based catalysts e.g. of ruthenium (Ru) or 77 iridium (Ir). ${ }^{[17,18]}$ Nevertheless, the low crustal reserve, high cost and poor stability of these 78 metals are obstacles for large-scale implementation of the noble-metal based electrocatalysts. 79 As an alternative, earth-abundant and cost-effective transition metal-based electrocatalysts are 80 promising candidates for OER. ${ }^{[19-22]}$ Rossmeisl and associates. ${ }^{[16]}$ constructed a volcano-type plot 81 showing the relationship between adsorption free energy descriptors ( $\Delta \mathrm{G}_{\mathrm{O}}$ and $\Delta \mathrm{G}_{\mathrm{HO}}$ ) and $\mathrm{OER}$

82 overpotential ( $\eta$ ), which can be used as a guide in searching for good OER catalysts. According to 83 their description, $\eta$ is determined by the critical step forming the $* 0$ (eq. 1.2) or $* O O H$ (eq. 1.3) 84 adduct. The difference in adsorption free energy for $* \mathrm{OH}$ and $* \mathrm{OOH}$ (Figure 1c) is a constant 85 (about $3.2 \mathrm{eV}$ ). ${ }^{[16,23]}$ Disregarding solvent dynamic effects (reorganization free energies) ${ }^{[24]}$, the 86 theoretical $\eta$ at standard conditions can be obtained by ${ }^{[16]}$

$87 \eta=\left\{\max \left[\left(\Delta \mathrm{G}_{\mathrm{O}} *-\Delta \mathrm{G}_{\mathrm{HO}}\right), 3.2 \mathrm{eV}-\left(\Delta \mathrm{GO}_{\mathrm{O}} *-\Delta \mathrm{G}_{\mathrm{HO}}\right)\right] / \mathrm{e}\right\}-1.23 \mathrm{~V}$

$88 \mathrm{RuO}_{2}$ is located close to the top of the volcano (Figure 1d), but some non-noble transition metal 89 oxides, e. g. $\mathrm{NiO}$ and $\mathrm{CO}_{3} \mathrm{O}_{4}$, are found very close to $\mathrm{RuO}_{2}$. Transition metal-based catalysts could 90 be optimized by adjusting $\left(\Delta \mathrm{G}_{\mathrm{O}^{*}}-\Delta \mathrm{G}_{\mathrm{HO}}{ }^{*}\right) .{ }^{[25,26]}$ For example, Ho and co-workers have reported 91 that the (012) facet of $\alpha-\mathrm{Fe}_{2} \mathrm{O}_{3}$ (Figure 1e) has an optimal adsorption/desorption position for 92 favorable OER. ${ }^{[25]}$ 

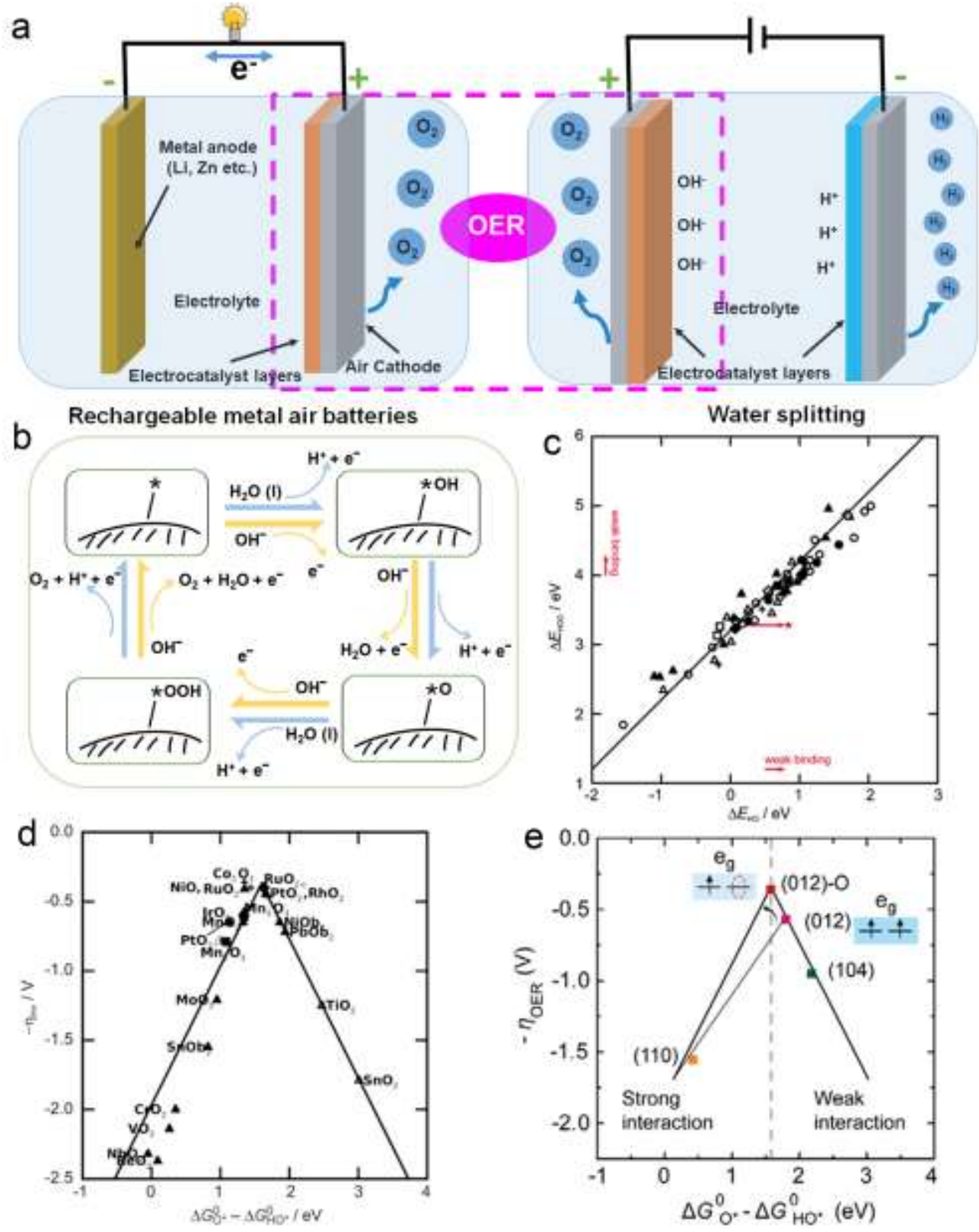

Figure 1. a) Schematic illustration of rechargeable metal-air batteries and electrochemical water

95 splitting. The magenta dashed box highlights the key process, i.e. OER in both devices. b) The OER 96 mechanism under acidic (blue round) and alkaline (orange round) conditions. Not drawn to real

97 scale. c) The universal scaling relation plot between adsorption energies of $\mathrm{HOO}^{*}$ and $\mathrm{HO}^{*}$ on 98 perovskites, rutiles, anatase, $\mathrm{Mn}_{\mathrm{x}} \mathrm{O}_{\mathrm{y}}, \mathrm{Co}_{3} \mathrm{O}_{4}$, and $\mathrm{NiO}$ oxides. The red star indicates the ideal 99 electrocatalyst. Reprinted with permission from Ref. ${ }^{[16]}$. Copyright (2011) WILEY-VCH Verlag $100 \mathrm{GmbH} \&$ Co. KGaA, Weinheim. d) Volcano plot of the computed OER overpotential against the 101 descriptor value of $\Delta G_{O^{*}}-\Delta G_{H O}$ for selected transition-metal oxides. Reprinted with permission 
102 from Ref. ${ }^{[16]}$. Copyright (2011) WILEY-VCH Verlag GmbH \& Co. KGaA, Weinheim. e) Impact of 103 facets on the OER activity descriptor. Inset, e $e_{g}$ occupancy of six- and seven- coordinated 104 configurations. Reprinted with permission from Ref. ${ }^{[25]}$ Copyright (2018) WILEY-VCH Verlag $105 \mathrm{GmbH} \&$ Co. KGaA, Weinheim.

106 As an emerging group of transition metal-based materials, metal-organic frameworks (MOFs) 107 are a class of highly porous crystalline materials composed of transition metal units and strongly 108 coordinating organic ligands. ${ }^{[27]}$ MOFs are being studied extensively with wide-ranging 109 application prospects, e.g. in gas storage and separation, batteries, catalysts etc., benefiting from 110 their high specific surface area, tunable porosity and abundance of active metal sites. ${ }^{[28,29]}$ To 111 date, a large library of MOFs has been fabricated with a wide spectrum of metal units or clusters 112 ("nodes") and organic linkers. ${ }^{[9,30]}$ Besides the variety of components and structures, different 113 morphologies of MOFs have been designed and prepared, including zero-dimensional (OD, e.g. 114 nanoparticles or quantum dots), one-dimensional (1D, e.g. nanowires or nanorods), two115 dimensional (2D, e.g. nanosheets or plates) and three-dimensional (3D, e.g. networks) 116 structures. ${ }^{[31-35]}$ These different morphologies and microstructures open new research 117 opportunities for OER if using them as precursors or templates for good OER catalytic 118 performance.

119 Since the discovery of graphene, ${ }^{[36]}$ 2D materials (e.g. MoS 2 , MXenes and black phosphorus) have 120 been widely studied in the past decades due to their unique physicochemical features. ${ }^{[37-42]}$ OER 121 is an interfacial reaction that is strongly dependent on the surface physicochemical features of 122 the catalysts. Graphene is composed of a single atomic layer of sp²-hybridized carbon atoms. 123 MXenes are transition metal carbides with hydrophilic nature due to their hydroxyl- or oxygen124 terminated surfaces. ${ }^{[43]}$ Different from graphene and MXenes, 2D MOFs are made by linking 125 metal nodes and organic linkers with coordination bonds. 2D MOFs themselves show OER 126 catalytic activity, offering additional advantages, i.e. easily tailored surface atom and bonding 127 organization for superior OER electrocatalysis. However, so far MOFs have been considered to 128 have low electrical conductivity and often poor OER performance. Recently, $\pi$-conjugated 2D 129 MOFs with benzene- or phthalocyanine-based organic groups have been synthesized, and 130 directly used for OER with high intrinsic electrical conductivity. ${ }^{[44,45]}$ 2D MOFs further combined 
131 with conductive agents (carbon components or conductive substrates), or pyrolysis of 2D MOFs

132 have been adopted to improve the conductivity and enhance OER catalytic activity. It is therefore

133 not surprising that 2D MOF-based materials are emerging as novel type efficient OER 134 electrocatalysts, but there are so far only few reviews focusing on the advances in 2D MOF-based

135 OER electrocatalysts.

136 Herein, we critically summarize recent progress in the preparation and characterization of 2D

137 transition metal-based MOFs (e.g. of $\mathrm{Ni}, \mathrm{Co}$ and $\mathrm{Cu}$ ), as well as their derivatives including the 138 corresponding metals/alloys, metal oxides/chalcogenides and metal phosphides/hydroxides for

139 OER electrocatalysis. Design principles and preparation routes are presented. The performance 140 of the electrocatalysts is directly compared in terms of $\eta$ (thermodynamics) and electrocatalytic 141 current density (kinetics), as well as operational stability (economics). Challenges and 142 perspectives are also discussed. Tables 1-3 provide numerical overview of reported materials 143 based on $\mathrm{Ni}, \mathrm{Co}, \mathrm{Cu}$ and derivatives, and performance metrics, while Figure 9 gives a graphical 144 summary of the evolution of publications, overpotential and achieved stabilities.

\section{Preparation and characterization of 2D MOFs}

2D MOFs can be synthesized via either top-down or bottom-up approaches. ${ }^{[9,30,46,47]}$ More detailed review focusing on synthesis methods of 2D MOF materials are available in literature ${ }^{[47,}$ ${ }^{48]}$. The top-down methods include physical ${ }^{[49,50]}$ and chemical exfoliation ${ }^{[51,52]}$, which rests on breaking the weak van der Waals interactions between layers in bulk layered materials. For example, Moorthy and co-workers ${ }^{[49]}$ synthesized 2D Cd-DP MOF nanosheets by ultrasonicating layered Cd-DP MOFs in ethanol. Scanning electron microscopy (SEM) (Figure 2a) showed the

152 presence of stacked 2D sheets from the solvothermal formation of the bulk MOF. Transmission

153 electron microscopy (TEM) of the 2D Cd-DP MOF obtained after ultrasonication displayed a 154 sheet-like morphology with wrinkles (Figure 2b). The thickness of 2D Cd-DP nanosheet, 155 determined by atomic force microscopy (AFM, Figure $2 \mathrm{c}$ and d) was about $3 \mathrm{~nm}$. Zhang and 156 associates $^{[52]}$ fabricated $2 \mathrm{~nm} \quad 2 \mathrm{D} \quad \mathrm{Co}_{6}-\mathrm{O}(\mathrm{dhbdc})_{2}(\mathrm{OH})_{2}\left(\mathrm{H}_{2} \mathrm{O}\right)_{10} \quad$ (dhbdc: 2,3-dihydroxy-1,4157 benzenedicarboxylic) nanosheets (2D-Co-NS) through electrochemical exfoliation by removing 158 the pillar ligands $\left(\mathrm{H}_{4} \mathrm{dhbdc}\right)$ in the 3D MOF. The prepared 2D-Co-NS showed a catalytic OER 
performance on nickel foams (NFs) with a low overpotential of $0.2 \mathrm{~V}$. 2D MOFs synthesized by top-down methods often exhibit inhomogeneous morphologies and thicknesses, attributed to numerous surface defects originating from the breakup of interlayer interactions in the 3D MOF precursors. Moreover, the abundant surface defects on the 2D MOFs are helpful for catalytic applications. ${ }^{[48,52]}$
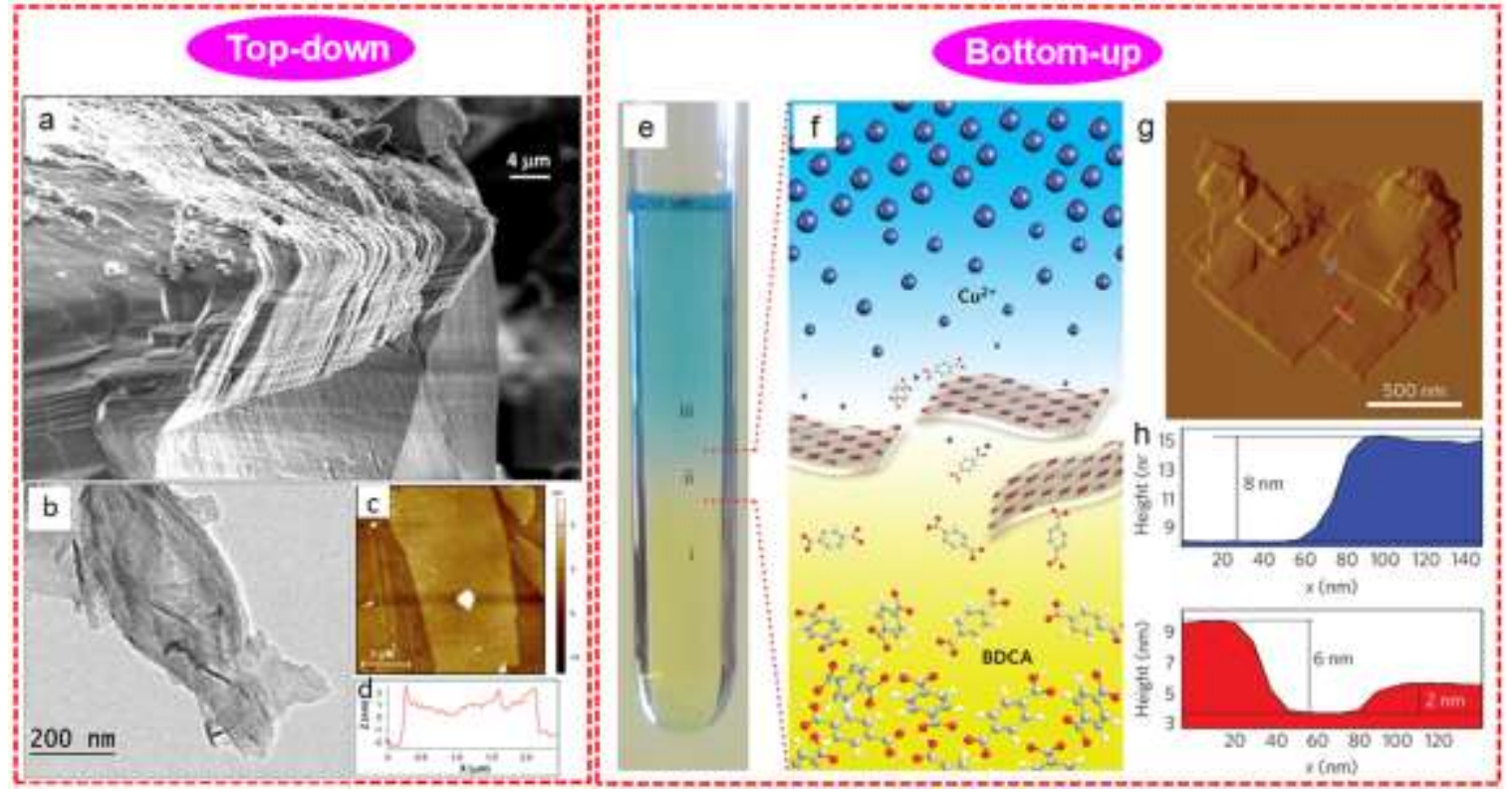

Figure 2. Examples of top-down (left) and bottom-up (right) approaches to 2D MOF synthesis. a) SEM image of pristine Cd-DP crystals show the presence of stacked 2D sheets. b) TEM and c) AFM images and d) height profile of 2D Cd-DP nanosheets. Reprinted with permission from Ref. ${ }^{[49]}$. Copyright (2018) Elsevier. e) Digital photograph, and f) Scheme that shows the spatial arrangement of different liquid regions during the synthesis of CuBDC MOF nanosheets. Regions labelled i, ii and iii correspond to benzene 1, 4-dicarboxylic acid (BDCA) solution, intermediate solution region containing the generated $\mathrm{CuBDC} \mathrm{MOF}$, and the aqueous solution of $\mathrm{Cu}^{2+}$ ions, respectively. g) AFM image of CUBDC MOF nanosheets. h) Height profiles measured along the

174 Publishing Group.

175 In contrast to the top-down method, the morphology and thickness of synthetic 2D MOFs by

176 bottom-up approaches can be well controlled, leading to high-quality and high-yield production.

177 Common bottom-up strategies include two-phase interfacial/intermediate layer growth ${ }^{[53,54]}$ or 
178 surfactant/template-assisted approach ${ }^{[55,56]}$. For example, Gascon and co-workers ${ }^{[53]}$ prepared 179 dispersible 2D copper 1,4-benzenedicarboxylate MOF (CuBDC) nanosheets through the two180 phase method (Figure 2e). $\mathrm{Cu}^{2+}$ ions and BDC linkers slowly diffuse to the interface of two 181 solutions, generating highly diluted 2D CuBDC nanosheets. AFM images (Figure 2f-h) 182 demonstrate lateral dimensions above one micrometer and thicknesses in the range 5-25 $\mathrm{nm}$. 183 Zhang et al. ${ }^{[56]}$ synthesized 2D zeolitic imidazolate framework-L (ZIF-L) nanosheets by template184 assisted deposition. Horizontally aligned 1D halloysite nanotubes were used as templates, acting as nucleation sites and guiding the vertical growth of the 2D MOF. Although the weak structural 186 stability and surface additives of 2D MOFs fabricated by bottom-up approaches are obstructive 187 for the application in surface-related applications, it is easy to control the formation of various 188 metal-doped 2D MOFs. ${ }^{[48,57]}$

189 Hybrid 2D MOFs resulting from the introduction of hetero-components (atoms, molecules etc.) 190 into the 2D MOF structure could efficiently inherit the controllable morphology but modify the 191 electronic structure to facilitate the catalytic activity for the OER. The most universal and facile 192 approach to synthesizing hybrid 2D MOFs is adding extra metal ions or metal-organic compounds 193 during the formation of 2D MOFs, the metal nodes of which are thus partially replaced or 194 modified by the foreign metal ions or metal-organic compounds. In addition, the template195 assisted approach is another emerging method to fabricate hybrid 2D MOFs featuring superior 196 interfacial connection for good electrical conductivity, robust structural stability and thus good

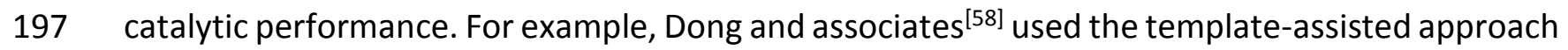
198 to prepare ultrathin $\mathrm{Co}_{9} \mathrm{Ni}_{1}-\mathrm{MOF}$ nanosheet arrays on $\mathrm{Co}_{9} \mathrm{Ni}_{1}$ foam substrates. The surface layer 199 of the metallic $\mathrm{Co}_{9} \mathrm{Ni}_{1}$ self-dissociated in the presence of benzenedicarboxylic acid (BDC) solution 200 during a hydrothermal process, forming 2D Cog $\mathrm{Ni}_{1}-\mathrm{MOF}$ nanosheet arrays on the substrate. This 201 2D MOF exhibited good OER catalytic activity with an overpotential $\eta$ of $215 \mathrm{mV}$ at $10 \mathrm{~mA} \mathrm{~cm}^{-2}$.

202 The morphology and structure of 2D MOFs can be characterized by a variety of techniques. SEM 203 and TEM can be used for the observation of the spontaneous curling at 2D MOF edges after 204 drying, while the thickness can be precisely measured by AFM. Further, the atomic arrangement 205 in 2D MOFs can be identified via scanning TEM (STEM) with near-atomic resolution and high Z206 contrast. ${ }^{[59]}$ The crystallinity of 2D MOFs can be examined by bulk powder X-ray diffraction (PXRD) 
207 or selected-area electron diffraction (SAED) of individual nanosheet. The elemental composition 208 can be obtained by energy dispersive spectroscopy (EDS) and X-ray photoelectron spectroscopy 209 (XPS), which also allows for chemical analysis of the elemental components in the 2D MOF. In 210 addition, EDS mapping using STEM can image the distribution of metal nodes in bimetallic or 211 trimetallic 2D MOFs with high resolution. X-ray absorption spectroscopy (XAS) with synchrotron 212 radiation can help to analyze oxidation states, local atomic structure and unoccupied metal 213 electronic states in 2D MOFs associating with intrinsic OER catalytic activity. ${ }^{[60]}$

214 Different electrode substrates and electrode preparation routes are employed when 2D MOF215 based materials are used for OER electrocatalysis. Drop-casting of the as-fabricated 2D MOF inks 216 onto a glassy carbon electrode (GCE), fluorine-doped tin oxide (FTO) on glass, or carbon cloth (CC) 217 is a widely used approach. ${ }^{[8,45,61,62]}$ It allows efficient control of the mass loading of the catalyst 218 on the substrate for quantitative investigation of the intrinsic catalytic OER activity. However, the 219 interface between the substrate and the catalysts may suffer considerable impedance as 220 insulating binders are typically used in the ink, leading to reduced OER performance. In-situ 221 strategies to grow 2D MOFs directly on conductive substrates, such as NFs, is an alternative, more 222 promising approach. ${ }^{[63,64]}$ The resulting 2D MOF electrodes not only maintained good electronic 223 connection between substrate and catalyst improving the electrical conductivity, but also inherit

224 the hierarchical frameworks of the substrates for improved $\mathrm{O}_{2}$ mass transport away from the 225 catalyst surface and good OER performance. However, determination of the precise mass loading 226 of catalysts in these systems is difficult. Furthermore, it is recommended to report the catalyst 227 loading and effective surface area so that appropriate comparison of OER performance across 228 studies can be made.

\section{3. 2D MOFs for the OER}

$2302 \mathrm{D}$ transition metal-based MOFs (e.g. of $\mathrm{Ni}$, $\mathrm{Co}$ and $\mathrm{Cu}$ ) have attracted extensive attention. 231 Among these, 2D Ni-based and Co-based MOFs have demonstrated excellent catalytic 232 performance for OER. 


\subsection{D Ni-based MOF hybrids}

234 2D Ni-based MOFs consisting of single-metal Ni units with different organic linkers have been 235 investigated in the past few years, as summarized in Table 1. ${ }^{[45,62,65]}$ Du et al. ${ }^{[45]}$ utilized a 236 phthalocyanine (Pc) unit as a key organic fragment to construct a $\pi$-conjugated 2D NiPc-MOF via 237 a bottom-up method, exhibiting a layered morphology (thickness: 100-200 nm) as confirmed by 238 AFM. The NiPc-MOF registered an OER $\eta$ of $350 \mathrm{mV}$ at $10 \mathrm{~mA} \mathrm{~cm}^{-2}$ on a fluorine-doped tin oxide 239 (FTO) substrate. It could be concluded that lack of heteroatom doping in the 2D NiPc-MOF and 240 low loading may limit the OER performance (Table 1). Similarly, a 2D pure Ni-based MOF, which 241 was prepared by physical exfoliation by ultra-sonicating 3D pillared-layer MOFs $242\left(\left[\mathrm{M}_{2}(\mathrm{BDC})(\right.\right.$ dabco $\left.)\right] \cdot-$ guest $(\mathrm{M}=\mathrm{Ni}, \mathrm{BDC}=1$,4-benzenedicarboxylate, dabco = 1,4-diazabicyclo243 [2.2.2] octane)) in water, showed an OER $\eta$ of $581 \mathrm{mV}$ at $10 \mathrm{~mA} \mathrm{~cm}^{-2}$ on CC. ${ }^{[62]}$ However, there is 244 still ample room for improvement in OER performance (Table 1). Recently, some researchers 245 have introduced metal heteroatoms to 2D Ni MOFs as hybrid electrocatalysts, enabling improved 246 OER performance. ${ }^{[4,66,67]}$ Tang and co-workers ${ }^{[44]}$ fabricated NiCo-based ultrathin 2D MOF 247 (NiCo-UMOFNs) consisting of $\mathrm{Ni}^{2+} / \mathrm{Co}^{2+}$ and organic linkers of $\mathrm{BDC}$ nanosheets with a uniform 248 thickness of $3.1 \mathrm{~nm}$ via sonication, exhibiting superior OER catalytic activity with a lower $\eta(250$ $249 \mathrm{mV}$ at $10 \mathrm{~mA} \mathrm{~cm}^{-2}$ ) than that of the single-metal 2D Ni-UMOFN (321 mV). In-situ X-ray absorption 250 spectroscopy (XAS) indicated that the Ni K-edge peaks of NiCo-UMOFNs shifted to higher binding 251 energy after applying a potential in the range of 1.43 to $1.53 \mathrm{~V}$ vs. RHE, confirming that the $\mathrm{Ni}$ 252 sites in NiCo-UMOFNs were more easily oxidized to high valence for enhanced catalytic sites than 253 in bulk NiCo-MOFs. ${ }^{[44,68]}$ Density functional theory (DFT) calculation results further revealed that 254 coordinatively unsaturated metal atoms were the main active sites and the coupling effect 255 between $\mathrm{Ni}$ and Co metals was crucial for the enhancement of electrocatalytic activity. In addition, 256 the nanometer-thick 2D structure increases the amount of exposed surface and thus of 257 unsaturated active metal sites. ${ }^{[44]}$ Following this report, a number of bimetallic 2D Ni-based MOFs 258 hybrids ( $\mathrm{NiFe}-\mathrm{UMNs}^{[66]}$ and $\mathrm{Ni}_{0.75} \mathrm{Fe}_{0.25} \mathrm{BDC}^{[67]}$ ) have been explored by a similar bottom-up 259 synthetic method with high quality and yield. For instance, Wang and associates ${ }^{[66]}$ synthesized 260 NiFe 2D ultrathin MOF nanosheets with a thickness of $\sim 10 \mathrm{~nm}$, showing a $\eta$ of $260 \mathrm{mV}$ at $10 \mathrm{~mA}$ $261 \mathrm{~cm}^{-2}$. Meanwhile, Li et al. ${ }^{[67]}$ tuned the Fe doping in a 2D Ni MOF, with the optimized $\mathrm{Ni}_{0.75} \mathrm{Fe}_{0.25}$ 
$262 \mathrm{BDC}$ registering a $\eta$ of $310 \mathrm{mV}$ at $10 \mathrm{~mA} \mathrm{~cm}^{-2}$. These reports indicate that the heteroatom (Co, $\left.\mathrm{Fe}\right)$

263 doping in the 2D Ni MOFs could efficiently maintain 2D morphology and modulate the electronic

264 structure for excellent OER performance. Introduction of metal heteroatoms in the 2D MOFs is 265 facile. Unsaturated metal atoms exposed at the surface of 2D MOFs can be easily replaced by 266 metal heteroatoms.

267 Table 1. OER activity of reported 2D Ni-based MOFs electrocatalysts in $1 \mathrm{M} \mathrm{KOH}$. The widely 268 different Tafel slopes are notable and indicative of quite different rate determining OER steps on 269 the different MOF surfaces.

\begin{tabular}{|c|c|c|c|c|c|c|}
\hline Catalyst & $\begin{array}{c}\text { Overpotential } \\
@ 10 \mathrm{~mA} \mathrm{~cm}{ }^{-2}(\mathrm{mV})\end{array}$ & $\begin{array}{l}\text { Tafel slope } \\
\left(\mathrm{mV} \text { dec }^{-1}\right)\end{array}$ & $\begin{array}{c}\text { Catalytic } \\
\text { stability (h) }\end{array}$ & $\begin{array}{l}\text { Loading } \\
\left(\mathrm{mg} \mathrm{cm}^{-2}\right)\end{array}$ & Substrate & Ref. \\
\hline NiPc-MOF & 350 & $\mathrm{~N} / \mathrm{A}$ & 50 & 0.076 & FTO & [45] \\
\hline 2D-Ni-single-layer & 581 & 182 & N/A & 0.2 & $\mathrm{CC}$ & [62] \\
\hline $\mathrm{NH}_{2} \mathrm{TA}-\mathrm{MOF}$ & 356 & 105 & 3.3 & $\mathrm{~N} / \mathrm{A}$ & GCE & [65] \\
\hline Ni-UMOFNs & 321 & 65 & $\mathrm{~N} / \mathrm{A}$ & 0.2 & GCE & [44] \\
\hline $\mathrm{Ni}$ BDC & 420 & 92.5 & N/A & 0.2 & GCE & [67] \\
\hline Ni-MNS/NF & 425@50 mA cm-2 & 100 & N/A & $\mathrm{N} / \mathrm{A}$ & $\mathrm{NF}$ & [63] \\
\hline Ni-MOF & 370 & 139 & N/A & 0.2 & GCE & [69] \\
\hline NiCo-UMOFNs & 250 & 42 & 120 & 0.2 & GCE & {$[44]$} \\
\hline NiFe-UMNs & 260 & 30 & 2.8 & 0.4 & GCE & [66] \\
\hline $\mathrm{Ni}_{0.75} \mathrm{Fe}_{0.25} \mathrm{BDC}$ & 310 & 43.7 & 11.1 & 0.2 & GCE & [67] \\
\hline Ni-MOF@Fe-MOF & 265 & 82 & $N / A$ & 0.2 & GCE & [69] \\
\hline $\mathrm{Ni}-\mathrm{BDC} / \mathrm{Ni}(\mathrm{OH})_{2}$ & 320 & 41 & 20 & 0.19 & GCE & [70] \\
\hline $\begin{array}{c}\text { NiFe MOF/OM- } \\
\text { NFH }\end{array}$ & 270 & 123 & 11.1 & 0.4 & GCE & [71] \\
\hline NiFeZn-MNS/NF & $350 @ 50$ mA cm ${ }^{-2}$ & 49 & 120 & N/A & NF & [63] \\
\hline Ni-ZIF/Ni-B@NF-4 & 234 & 57 & 36 & $\mathrm{~N} / \mathrm{A}$ & $\mathrm{NF}$ & [72] \\
\hline
\end{tabular}

270 N/A: not available.

271 In addition, incorporating heterogeneous components into 2D Ni-based MOFs can also enhance

272 the catalytic ability for water oxidation. ${ }^{[69-72]}$ Rational design of the composition and structure 273 could efficiently mitigate the aggregation of 2D Ni MOF. For example, Sun et al. ${ }^{[69]}$ synthesized

274 hybrid 2D dual MOFs (Ni-MOF@Fe-MOF) by in-situ generation of Fe-MOFs nanocrystals on the 275 surface of 2D Ni MOFs, resulting in a $100 \mathrm{mV}$ lower overpotential (to $265 \mathrm{mV}$ at $10 \mathrm{~mA} \mathrm{~cm}^{-2}$ ). Qiao 276 and coworkers ${ }^{[70]}$ developed a $2 \mathrm{D} \mathrm{Ni-BDC} / \mathrm{Ni}(\mathrm{OH})_{2}$ heterostructure for OER electrocatalysis, 277 exhibiting a $\eta$ of $320 \mathrm{mV}$ at $10 \mathrm{~mA} \mathrm{~cm}^{-2}$ and a good catalytic durability of $20 \mathrm{~h}$. Besides, Zhu et 278 al. ${ }^{[71]}$ designed a unique 2D NiFe MOF nanosheets inlayed on a 3D ordered macroporous NiFe 
279 hydroxide template (NiFe MOF/OM-NFH), with partial NiFe hydroxide of the template in-situ 280 transformed into 2D NiFe MOF nanosheets. The combination of the highly exposed active centers 281 in the ultrathin NiFe MOF nanosheet inlay and efficient electron/mass transfer in the 3D 282 hierarchical structure ensured excellent OER catalytic activity, with a $\eta$ of $270 \mathrm{mV}$ at $10 \mathrm{~mA} \mathrm{~cm}^{-2}$. 283 In addition, generating hybrid 2D Ni MOFs on porous NF skeletons could accelerate mass/charge 284 transfer. Wei and co-workers ${ }^{[63]}$ grew NiFeZn-based MOF nanosheets containing $\mathrm{Fe}_{2} \mathrm{O}_{3}$ 285 nanoparticles (size $<5 \mathrm{~nm}$ ) on NF substrates (NiFeZn-MNS/NF), registering better OER 286 performance (350 mV@ $50 \mathrm{~mA} \mathrm{~cm}{ }^{-2}$ ) than the pure Ni- MNS/NF (425 mV@ $50 \mathrm{~mA} \mathrm{~cm}^{-2}$ ). It is 287 notable that crystalline-amorphous interfaces on the crystalline surface of Ni-based MOFs could 288 optimize the adsorption energy of OER intermediates for enhanced OER performance. Wu and 289 associates $^{[72]}$ synthesized ultrathin $\mathrm{Ni}$-ZIF/Ni-B nanosheets with abundant crystalline-amorphous 290 phase boundaries via room temperature boronization of as-prepared Ni-ZIF nanorods on NF 291 (Figure 3a). High-resolution TEM (HRTEM) (Figure 3b-d) clearly showed the crystalline-to292 amorphous transformation process from Ni-ZIF to Ni-B with boronization time. The optimal 293 samples (Figure 3c) with $4 \mathrm{~h}$ boronization (Ni-ZIF/Ni-B@NF-4) contained a large number of 294 crystalline-amorphous phase boundaries. The corresponding STEM and EDS mapping (Figure 3e) 295 revealed the co-existence and uniform dispersion of $\mathrm{C}, \mathrm{N}, \mathrm{Ni}$ and $\mathrm{B}$. Among various controls, $\mathrm{Ni}-$ 296 ZIF/Ni-B@NF-4 exhibited the best catalytic activity for OER (Figure 3f and g) with the lowest $\eta$ of $297234 \mathrm{mV}$ at $10 \mathrm{~mA} \mathrm{~cm}{ }^{-2}$ and highest catalytic stability, with negligible decay after $36 \mathrm{~h}$ at $10 \mathrm{~mA}$ $298 \mathrm{~cm}^{-2}$ by maintaining the initial 2D nanosheet morphology (inset of Figure 3g). DFT calculations 299 indicated that the potential-determining step (PDS) of Ni-ZIF was the adsorption of * OH (2.36 eV 300 at $\mathrm{U}=1.23)$, while the PDS was the formation of $* \mathrm{OOH}(1.23 \mathrm{eV}$ at $\mathrm{U}=1.23$ ) for amorphous Ni-B. 301 The combination of 2D Ni-ZIF and amorphous Ni-B reduced the energy barrier of adsorption of $302 * \mathrm{OH}$ and formation of ${ }^{*} \mathrm{OOH}$, leading to enhanced intrinsically OER catalytic activity. 

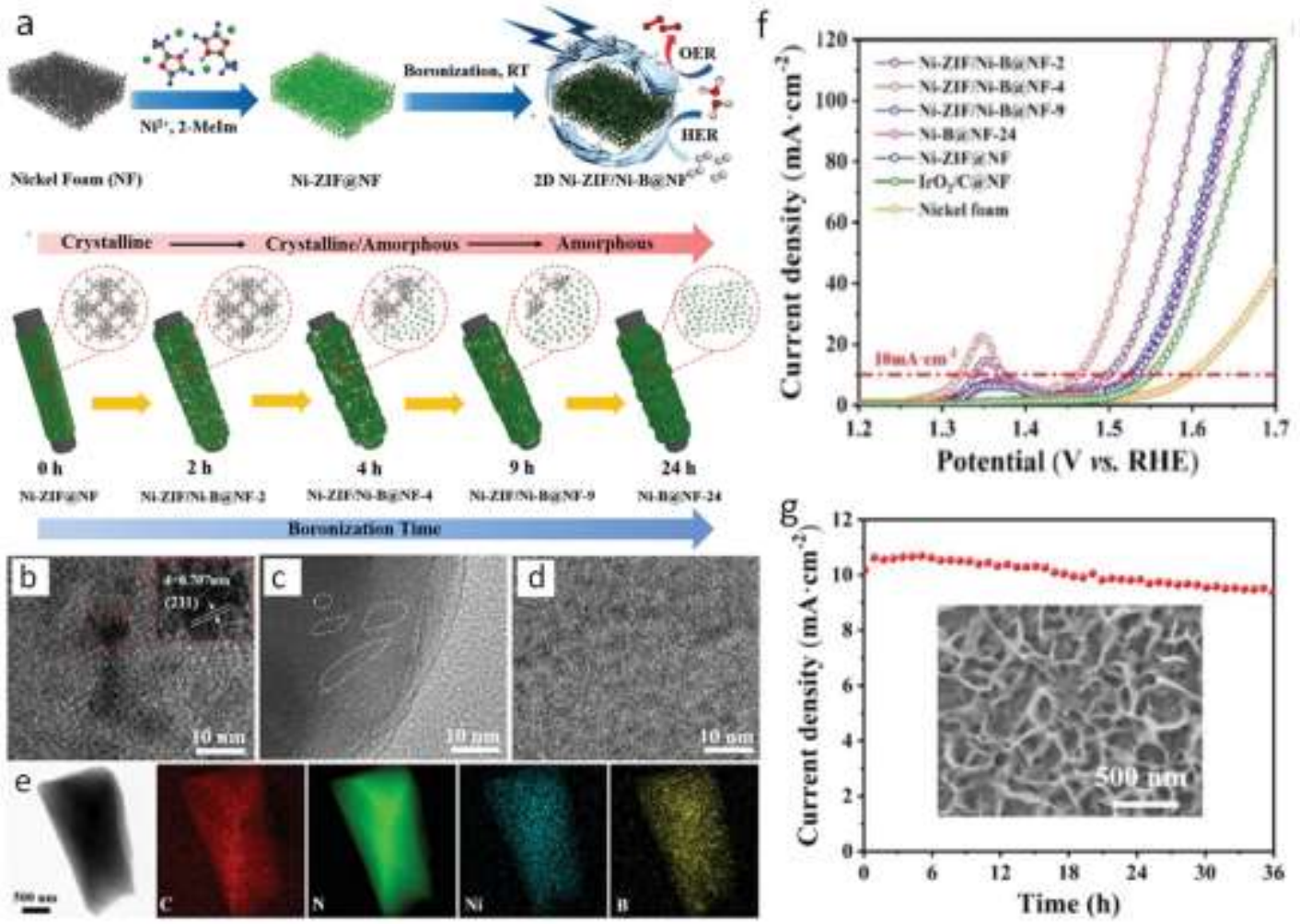

Figure 3. a) Schematic illustration of the synthesis process of Ni-ZIF/Ni-B@NF. HRTEM images of b) Ni-ZIF, c) Ni-ZIF/Ni-B-4, and d) Ni-B@NF-24. e) STEM and the corresponding EDS elemental mapping of Ni-ZIF/Ni-B-4. f) OER performance of Ni-ZIF@NF, Ni-ZIF/Ni-B@NF-2, Ni-ZIF/Ni-B@NF4, Ni-ZIF/Ni-B@NF-9, and Ni-B@NF-24 characterized by LSV with a scan rate of $1 \mathrm{mV} \mathrm{s} \mathrm{s}^{-1}$ in $1.0 \mathrm{M}$ $\mathrm{KOH} . \mathrm{g})$ The operational stability of Ni-ZIF/Ni-B@NF-4 at $1.464 \mathrm{~V}$ vs. RHE. Inset in (g) is an SEM image of the cycled Ni-ZIF/Ni-B@NF-4 catalyst after long-term test. Reprinted with permission from Ref. ${ }^{[72]}$. Copyright (2019) WILEY-VCH Verlag GmbH \& Co. KGaA, Weinheim.

311 In summary, 2D Ni-based MOFs hybrids used for OER have been studied over several years

312 recently. Most pristine 2D Ni MOFs demonstrate relatively weak OER catalytic capacity due to 313 the poor catalytic activity of active sites and strong tendency to agglomerate during OER, in turn

314 leading to limited catalytic stability. Heterogeneous metal atoms or compounds are therefore 315 introduced in the 2D Ni MOFs to modulate the electronic structure for enhanced intrinsic 316 catalytic activity and in the agglomeration for improved catalytic stability. Some improvement 317 has been achieved (Table 1), while the detailed understanding of OER catalytic mechanism is still 318 ahead of us. 


\subsection{D Co-based MOF hybrids}

320 2D Co-based MOFs also exhibit high catalytic OER performance, as summarized in Table 2. 2D 321 single-metal Co-based MOFs with a range of organic linkers have been studied recently. ${ }^{[52,64,73-}$

$322{ }^{75]}$ For example, Fischer and associates ${ }^{[73]}$ utilized 2D cobalt ion $\left(\mathrm{Co}^{2+}\right)$ and benzimidazole (blm) to 323 prepare zeolite-imidazole framework (Co-ZIF-9(III)) nanosheets (thickness: 2-4 nm), via 324 mechanochemical grinding and subsequent ultrasonication assisted liquid-phase exfoliation. The 325 2D Co-ZIF-9(III) nanosheets exhibited a $\eta$ of $380 \mathrm{mV}$ at $10 \mathrm{~mA} \mathrm{~cm}{ }^{-2}$, better than that of bulk Co326 ZIF-9 counterparts ( $\mathrm{n}: 420 \mathrm{mV}$ ), which can be explained by more accessible active sites and faster 327 mass diffusion than bulk MOF crystals. Similarly, the introduction of a second organic linker to $3282 \mathrm{D}$ Co-based MOFs ${ }^{[74,75]}$ by top-down approaches can also enhance OER catalysis outperforming 329 bulk Co MOFs. Bu and co-workers ${ }^{[64]}$ provided a bottom-up method for in-situ growth of quasi$3302 \mathrm{D}$ Co MOF nanoarrays consisting of $\mathrm{Co}^{2+}$ and organic linkers of thiophenedicarboxylic acid $331\left(\mathrm{H}_{2} \mathrm{TDC}\right)$ on NF substrates (Co MOF/NF), with a slight reduction in $\eta$ relative to drop-casting the 332 same MOF powders on NF (270 vs $297 \mathrm{mV}$ at $10 \mathrm{~mA} \mathrm{~cm}{ }^{-2}$ ). The enhanced catalytic performance 333 was mainly attributed to the well-connected attachment of the catalyst on the hierarchical, 334 porous NF skeleton for fast electron/ion transfer.

335 Table 2. OER activity of reported 2D Co-based MOFs electrocatalysts in $1 \mathrm{M} \mathrm{KOH}$.

\begin{tabular}{|c|c|c|c|c|c|c|}
\hline Catalyst & $\begin{array}{c}\text { Overpotential } \\
@ 10 \mathrm{~mA} \mathrm{~cm}{ }^{-2}(\mathrm{mV})\end{array}$ & 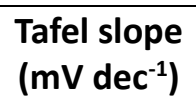 & $\begin{array}{l}\text { Catalytic } \\
\text { stability (h) }\end{array}$ & $\begin{array}{l}\text { Loading } \\
\left(\mathrm{mg} \mathrm{cm}^{-2}\right)\end{array}$ & Substrate & Ref. \\
\hline $\begin{array}{l}\text { Exfoliated } \\
\text { Co-ZIF-9(III) }\end{array}$ & 380 & 55 & 10 & 0.21 & GCE & [73] \\
\hline $\begin{array}{l}\text { 2D-Co- } \\
\text { NS@Ni }\end{array}$ & 211 & 46 & 96 & N/A & NF & {$[52]$} \\
\hline $\begin{array}{l}\text { Ultrathin Co- } \\
\text { MOF }\end{array}$ & 263 & 74 & 3.3 & 0.25 & GCE & [74] \\
\hline Co-MONs & 309 & 75.7 & 30 & N/A & $C P^{a}$ & [75] \\
\hline Co MOF/NF & 270 & 75 & 30 & N/A & $\mathrm{NF}$ & {$[64]$} \\
\hline Co-UMOFNs & 371 & 103 & N/A & 0.2 & GCE & [44] \\
\hline Co-MOF & 341 & 111 & $N / A$ & N/A & GCE & {$[76]$} \\
\hline $\begin{array}{l}\text { Co@HPA- } \\
\text { MOF }\end{array}$ & 386 & 61 & $N / A$ & 0.21 & GCE & [77] \\
\hline $\begin{array}{l}\text { CoNi(1:1)- } \\
\text { MOF }\end{array}$ & 265 & 56 & 20 & N/A & Cu foil & [76] \\
\hline
\end{tabular}




\begin{tabular}{|c|c|c|c|c|c|c|}
\hline $\begin{array}{c}\text { Co-Ni@HPA- } \\
\text { MOF }\end{array}$ & 320 & 58 & N/A & 0.21 & GCE & [77] \\
\hline $\mathrm{CO}_{3} \mathrm{Fe}-\mathrm{MOF}$ & 280 & 38 & 10 & 0.42 & GCE & [78] \\
\hline $\begin{array}{c}\text { FeCo-MNS- } \\
1.0\end{array}$ & 298 & 21.6 & 13.9 & 0.36 & GCE & [79] \\
\hline CoNi-MOFNA & 215 & 51.6 & 300 & 2.0 & $\begin{array}{l}\mathrm{Co}_{9} \mathrm{Ni}_{1} \\
\text { foam }\end{array}$ & [58] \\
\hline CoFe-MOF & 277 & 31 & N/A & 0.34 & GCE & [80] \\
\hline $\begin{array}{l}\mathrm{Ti}_{3} \mathrm{C}_{2} \mathrm{~T}_{x^{-}} \\
\text {CoBDC }\end{array}$ & 410 & 65 & N/A & 0.21 & GCE & [81] \\
\hline $\begin{array}{c}\text { Co-BPDC/Co- } \\
\text { BDC-3 }\end{array}$ & 335 & 72.1 & 80 & 0.28 & GCE & [82] \\
\hline CoBDC-FC-NF & 178 & 51 & 80 & 1.80 & NF & [83] \\
\hline
\end{tabular}

$336{ }^{a}$ CP: carbon paper.

337 In contrast to pure 2D Co MOFs, 2D hybrid Co-based MOFs with metal heteroatoms (e.g. Fe, Ni),

338 inheriting the controllable morphology and allowing for tailoring of the electronic structure, have 339 demonstrated improved OER catalytic activity. ${ }^{[58,76-80]}$ For example, Lee et al. ${ }^{[76]}$ grew 2D CoNi-

340 MOFs with different atom ratios of $\mathrm{Co}$ and $\mathrm{Ni}$ on $\mathrm{Cu}$ foil substrates using a hydrothermal 341 procedure. The optimal material, CoNi(1:1)-MOF (thickness: $5.3 \mathrm{~nm}$ ), showed a $\eta$ of $265 \mathrm{mV}$ at $34210 \mathrm{~mA} \mathrm{~cm}^{-2}$, which was lower than that of pure Co MOF (341 mV). In-situ conducting AFM and 343 two-point conductivity measurements indicated that the good catalytic activity was related to 344 the dominant $(2 \overline{2} 0)$ facets with enhanced conductivity along the Z-axis, facilitating electron 345 transfer from the substrate to active centers. Similarly prepared 2D bimetallic Co-based MOFs 346 including Co-Ni@HPA-MOF (HPA: hypoxanthine) ${ }^{[77]}$ and $\mathrm{Co}_{3} \mathrm{Fe} \mathrm{MOF}^{[78]}$ also showed enhanced 347 OER performance compared to the corresponding single-metal Co MOFs.

348 In addition, Zhu and co-workers ${ }^{[79]}$ designed a unique template-assisted approach to the 349 synthesis of iron-cobalt MOF-74 nanosheets (FeCo-MNS) by solvothermal reactions (Figure 4a). 350 As-prepared iron-cobalt oxide nanosheets (FeCo-ONS) were used as sacrificial templates for the 351 reaction with different amounts of 2,5-dihydroxyterephthalic acid ( $\mathrm{H}_{4}$ dobdc). TEM and AFM 352 images (Figure $4 \mathrm{~b}-\mathrm{c}$ ) indicated that FeCo-ONS transformed to the optimal FeCo-MNS-1.0 353 nanosheets (thickness: $2.6 \mathrm{~nm}$ ). FeCo-MNS-1.0 (Figure 4d) showed superior OER performance 354 with a lower $\eta\left(298 \mathrm{mV}\right.$ at $\left.10 \mathrm{~mA} \mathrm{~cm}^{-2}\right)$ and an unusually low Tafel slope $\left(21.6 \mathrm{mV} \mathrm{dec}^{-1}\right)$ compared 355 with those of FeCo-ONS, cobalt MOF-74 nanosheets (Co-MNS) and iron-cobalt bulk MOF-74 
356 (FeCo-MB). X-ray absorption fine structure (XAFS) characterization demonstrated an increased 357 amount of coordinatively unsaturated metal sites (CUMSs) on FeCo-MNS-1.0, which contributed 358 to the superior OER activity. Construction of 2D FeCo-MNS nanosheets with $2.6 \mathrm{~nm}$ thickness 359 enriches the CUMSs that act as active centres for enhanced OER performance. Besides, Jia and 360 associates $^{[80]}$ prepared hierarchically structured 2D CoFe-MOFs using ultrasound-assisted 361 synthesis and subsequent solvothermal treatment. This route could remove unstable domains 362 and generate continuous mesopores on the 2D MOFs in-situ, resulting in 2D CoFe-MOFs with 363 hierarchical porosity using holey ultrathin crystalline nanosheets (thickness: $1.3 \mathrm{~nm}$ ). The 364 designed 2D porous structure significantly improved the OER catalytic performance with a $\eta$ of 365 $277 \mathrm{mV}$ at $10 \mathrm{~mA} \mathrm{~cm}^{-2}$.

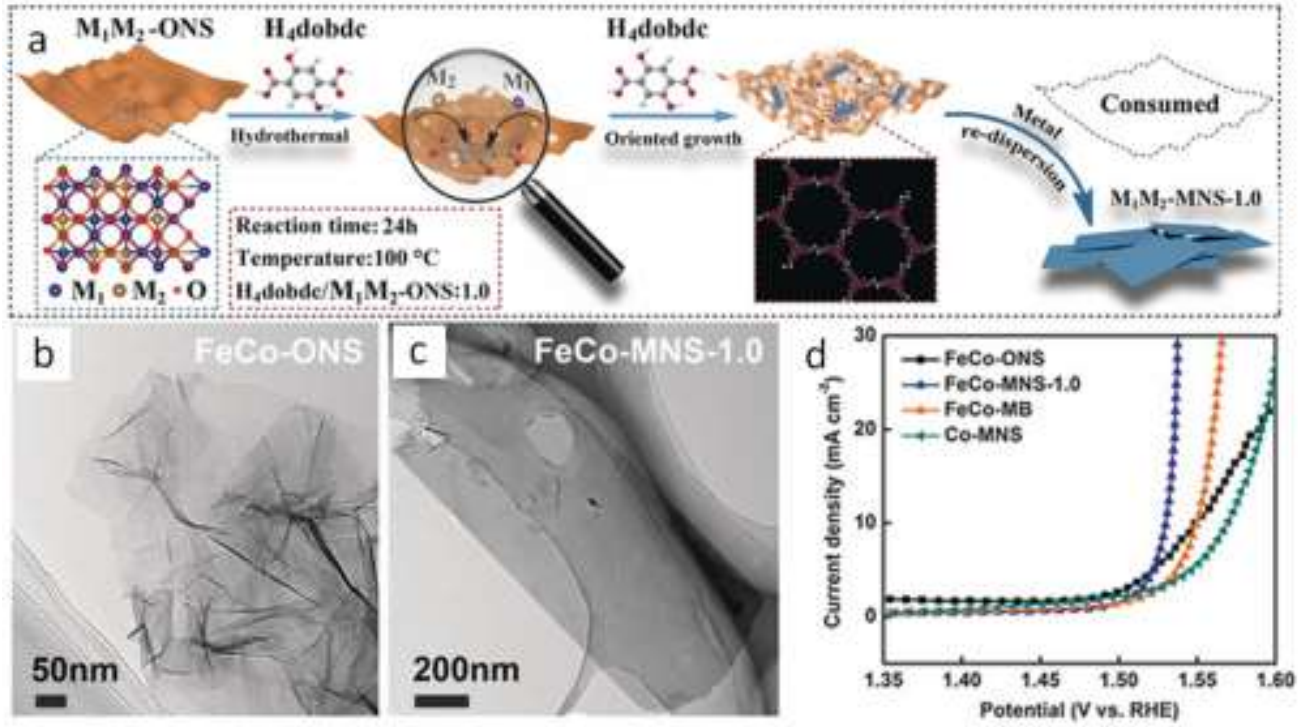

Figure 4. a) Schematic illustration of the sacrificial 2D metal oxide approach to achieving the conversion of M-ONS to M-MNS in the presence of $\mathrm{H}_{4}$ dobdc ligand. b) TEM image of FeCo-ONS. c) TEM image of FeCo-MNS-1.0. d) OER polarization curves of FeCo-ONS, FeCo-MNS-1.0, ironcobalt bulk MOF-74 (FeCoMB) and Co-MNS in $0.1 \mathrm{M} \mathrm{KOH}$. Reprinted with permission from Ref. ${ }^{[79]}$.

371 Copyright (2019) WILEY-VCH Verlag GmbH \& Co. KGaA, Weinheim.

372 There are also reports focusing on the combination of heterogeneous components and 2D Co-

373 based MOFs to optimize the electronic structure. ${ }^{[81-83]}$ Such hybridization can also assist in 374 preventing MOF nanosheet agglomeration. For instance, Huang's group ${ }^{[81]}$ incorporated 2D 375 cobalt 1,4-benzenedicarboxylate (CoBDC) with $\mathrm{Ti}_{3} \mathrm{C}_{2} \mathrm{~T}_{x}$ nanosheets via an inter-diffusion reaction- 
assisted process. An OER $\eta$ of $410 \mathrm{mV}$ at $10 \mathrm{~mA} \mathrm{~cm}{ }^{-2}$ was obtained with the hybrid $\mathrm{Ti}_{3} \mathrm{C}_{2} \mathrm{~T}_{\mathrm{x}}-\mathrm{CoBDC}$,

377 which was an improvement over the pure CoBDC. Metal-like $\mathrm{Ti}_{3} \mathrm{C}_{2} \mathrm{~T}_{\mathrm{x}}$ nanosheets promoted the

378 charge transfer kinetics of the hybrid material and prevented the porous CoBDC MOF layers from

379 aggregating. Besides, $\mathrm{Ni}$ and associates $^{[80]}$ reported a $2 \mathrm{D}$ Co-BPDC (BPDC: 4,4'-

380 biphenyldicarboxylate)/Co-BDC heterojunction nanostructure for OER electrocatalysis. Co-BPDC

381 was grown on pre-synthesized Co-BDC nanosheets under stirring at $80{ }^{\circ} \mathrm{C}$ for different periods of

382 time. The optimal electrocatalyst, Co-BPDC/Co-BDC-3, showed better OER performance ( $\eta$ of 335

$383 \mathrm{mV}$ at $10 \mathrm{~mA} \mathrm{~cm}^{-2}$ ) than that of Co-based MOFs. Li and co-workers ${ }^{[83]}$ incorporated non-bridging

384 linkers such as carboxyferrocene (Fc) into $\mathrm{Co}_{2}(\mathrm{OH})_{2}\left(\mathrm{C}_{8} \mathrm{H}_{4} \mathrm{O}_{4}\right)$ MOF nanosheets (CoBDC-Fc). DFT

385 simulation suggested that the modification of the electronic structure for CoBDC-Fc could change

386 the band gap and charge distribution, thus optimizing adsorption strengths of OER intermediates

387 (Figure 5a). SEM and TEM images (Figure 5b-d) of CoBDC-Fc showed nanosheet-like 388 morphologies and EDS mappings (Figure 5e) clearly indicated that Fc was homogeneously 389 incorporated. CoBDC-Fc (Figure $5 f-i$ ) gave a low $\eta$ of $178 \mathrm{mV}$ at $10 \mathrm{~mA} \mathrm{~cm}{ }^{-2}$, a Tafel slope of 51 $390 \mathrm{mV} \mathrm{dec}{ }^{-1}$ and long-term stability $(80 \mathrm{~h})$ at a high current density of $100 \mathrm{~mA} \mathrm{~cm}{ }^{-2}$. The improved 391 OER performance of COBDC-Fc indicates that OER activity of MOFs can be indeed facilitated by 392 tuning electronic structure via introducing Fc. DFT calculations showed that the PDS for CoBDC 393 was the formation of ${ }^{*} \mathrm{OH}$ with a large energy barrier ( $\left.3.74 \mathrm{eV}\right)$. This was reduced significantly on 394 Fc incorporation, which shifted the PDS to the generation of * $\mathrm{O}$ with a much lower energy barrier $395(1.85 \mathrm{eV})$.

396 Overall, 2D Co-based MOFs hybrids have been widely investigated for OER. Heterogeneous metal 397 atoms or compounds are introduced in the 2D Co-based MOFs to tune the electronic structure 398 and surface physicochemical features for enhanced OER catalytic activity. Compared with 2D Ni399 based MOFs hybrid, a wider range of 2D Co-based MOFs hybrids are obtained (Table 2), 400 demonstrating better OER catalytic performance and deeper understanding of the catalytic 401 mechanisms. 

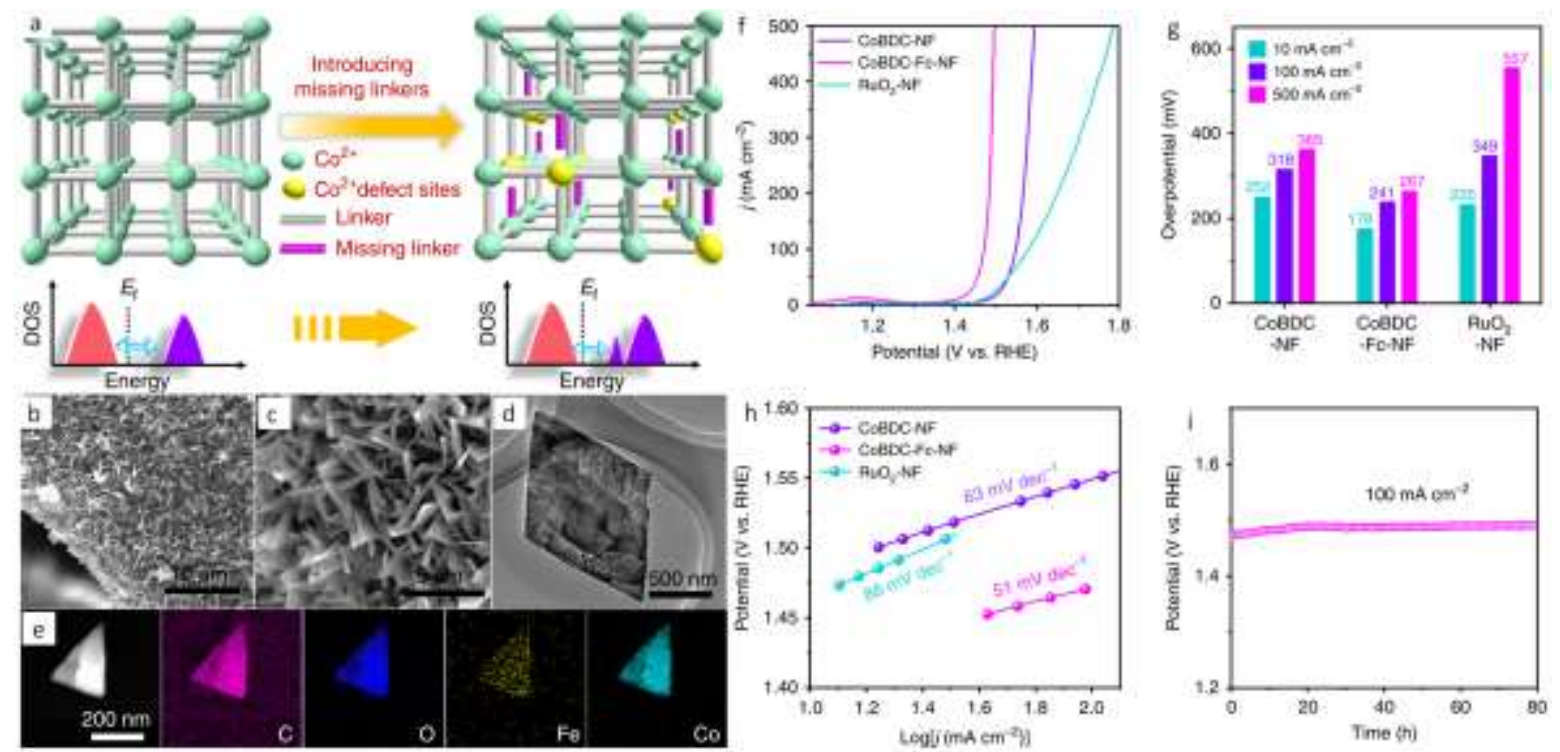

403 Figure 5. a) Modulating the electronic structure of CoBDC MOF via introduction of Fc for 404 improved OER. b-c) SEM and d) TEM images of CoBDC-Fc-NF. e) STEM image and STEM-EDS mappings of CoBDC-Fc-NF. f) LSV curves, g) overpotentials at different current densities and h)

406 Tafel plots of different catalysts toward OER in $1 \mathrm{M} \mathrm{KOH}$. i) Operational stability of CoBDC-Fc-NF 407 for $80 \mathrm{~h}$ at $100 \mathrm{~mA} \mathrm{~cm}{ }^{-2}$ in $1 \mathrm{M} \mathrm{KOH}$. Reprinted with permission from Ref. ${ }^{[83]}$. Copyright (2019) 408 Nature Publishing Group.

\subsection{D Cu-based MOF hybrids}

410 In addition to the widely investigated 2D Ni- or Co-based MOF hybrids for OER electrocatalysis, 411 the potentials of other 2D MOFs, especially Cu-based MOFs have been explored. ${ }^{[84-86]}$ For 412 example, $\mathrm{Fu}$ and associates ${ }^{[84]}$ prepared $\mathrm{CoNi}-\mathrm{Cu}(\mathrm{BDC})$ electrocatalysts by utilizing $\mathrm{Cu}(\mathrm{BDC})$ as a 413 template with a facile one-step impregnation approach, delivering a lower $\eta$ of $327 \mathrm{mV}$ at $10 \mathrm{~mA}$ $414 \mathrm{~cm}^{-2}$ than the pure $\mathrm{Cu}(\mathrm{BDC})$. The enhanced OER activity may be attributed to the transformed 2D 415 lamellar morphology and synergistic effects of the metal species. Thus, doping transition metal 416 heteroatoms ( $\mathrm{Ni}, \mathrm{Co}$ ) into the 2D Cu-based MOFs to modify the electronic structure could be a 417 promising route. Further, combining the hybrid 2D Cu-based MOFs with conductive materials 418 (say, graphene) can improve the electrical conductivity for fast electron transfer, leading to 419 enhanced OER catalytic activity. As an example, a 2D bimetallic porphyrinic MOF (Co-CuTCPP) 420 combined with reduced graphene oxide (Co-CuTCPP/rGO) exhibited a OER catalytic performance, 
421 with a $\eta$ of $396 \mathrm{mV}$ at $10 \mathrm{~mA} \mathrm{~cm}{ }^{-2}$ and a Tafel slope of $58 \mathrm{mV} \mathrm{dec}^{-1} .^{[85]}$ In addition, Fang's group ${ }^{[86]}$

422 combined CoCu-based zeolitic imidazolate framework nanosheets (CoCu-ZIF NSs) and 423 graphdiyne (GDY), to obtain good OER catalytic activity with a low $\eta$ of $250 \mathrm{mV}$ at $10 \mathrm{~mA} \mathrm{~cm}^{-2}$ and

424 Tafel slope of $57 \mathrm{mV} \mathrm{dec}{ }^{-1}$. This material is believed to benefit from the fast electron transport 425 ability and large number of exposed active sites. Considering that the price of $\mathrm{Cu}$ is lower than 426 the price of $\mathrm{Ni}$ and $\mathrm{Co}$, approaches to preparing 2D Cu-based MOFs as efficient OER 427 electrocatalysts are very appealing.

\section{4. 2D MOF derivatives for the OER}

429 Although 2D MOF electrocatalysts are intensively studied in the past few years, the unsatisfactory 430 stability and conductivity of 2D MOFs limit their further OER application. For example, Biradha 431 and associates ${ }^{[65]}$ synthesized a Ni MOF ( $\mathrm{NH}_{2}$ TA-MOF) composed of a flexible tripodal tris-pyridyl

432 ligand and 2-aminoterpthalate $\left(\mathrm{H}_{2} \mathrm{NTA}\right)$, displaying a $\eta$ of $356 \mathrm{mV}$ at $10 \mathrm{~mA} \mathrm{~cm}^{-2}$ and a poor 433 stability of $3.3 \mathrm{~h}$. Alternatively, 2D MOF derivatives, either with or without metal component, 434 obtained via pyrolysis in certain atmosphere and other post-treatment routes can potentially overcome these challenges. ${ }^{[48,87]}$ Among these, MOF-derived metal-free carbon materials exhibit

436 relatively poor OER catalytic performance, ${ }^{[88,89]}$ which is likely due to water oxidation occurring 437 at overpotentials, where oxidation of the carbon components can occur, compromising the 438 structure. This highlights the importance of metal components, which can be oxidized to high439 valence states and recycled between valences during OER catalysis, as the OER active site. 2D 440 MOF-derived metal-based components (e. g. metals/alloys, metal oxides/chalcogenides or metal 441 phosphides/hydroxides etc.) containing carbon materials demonstrate enhanced OER activity 442 and stability. ${ }^{[48,90]}$ 2D MOF derivatives can not only efficiently inherit the morphology and 443 structure of the 2D MOF precursors, but display porous or hierarchical nanostructures of carbon 444 with exposed metal sites on the surface for improved mass transfer. Moreover, the carbonaceous 445 components formed originating from the organic linkers can improve the electrical conductivity 446 for fast electron transfer and impart structural stability during OER. In this section, we summarize 447 recent advances (Table 3) in 2D transition metal-based MOF derivatives for OER electrocatalysis.

448 Table 3. OER activity of reported 2D MOF-derived electrocatalysts in $1 \mathrm{M} \mathrm{KOH}$. 


\begin{tabular}{|c|c|c|c|c|c|c|}
\hline Catalyst & $\begin{array}{c}\text { Overpotential } \\
@ 10 \mathrm{~mA} \mathrm{~cm}^{-2}(\mathrm{mV})\end{array}$ & $\begin{array}{l}\text { Tafel slope } \\
\left(\mathrm{mV} \text { dec }^{-1}\right)\end{array}$ & $\begin{array}{c}\text { Catalytic } \\
\text { stability (h) }\end{array}$ & $\begin{array}{l}\text { Loading } \\
\left(\mathrm{mg} \mathrm{cm}^{-2}\right)\end{array}$ & Substrate & Ref. \\
\hline Ni@NC & 280 & 45 & 10 & 0.31 & GCE & [91] \\
\hline HXP@NC800 & 307 & 48 & 8 & 0.4 & GCE & [92] \\
\hline Co-NCS@CNT & 360 & 92.9 & $N / A$ & 0.17 & GCE & [93] \\
\hline Co@N-carbon & 400 & 61 & $N / A$ & 0.21 & GCE & [94] \\
\hline FeNi@CNF & 356 & 62.6 & 24 & 0.34 & GCE & [95] \\
\hline Ni-MOF-250 & $250 @ 50 \mathrm{~mA} \mathrm{~cm}{ }^{-2}$ & 88.6 & 20 & N/A & NF & {$[96]$} \\
\hline $\begin{array}{c}\mathrm{CO}_{3} \mathrm{O}_{4} / \mathrm{C}_{\mathrm{BDC}} \\
\text { nanosheet arrays }\end{array}$ & 208 & 50.1 & 36 & N/A & Ni foil & [97] \\
\hline CoTFBDC/EG_250 & 365 & 39.8 & 10 & 0.25 & GCE & {$[98]$} \\
\hline $\mathrm{CO}_{3} \mathrm{O}_{4}$ flakes array & 205 & 65.3 & 24 & $\mathrm{~N} / \mathrm{A}$ & NF & {$[99]$} \\
\hline $\mathrm{M}-\mathrm{Co}_{3} \mathrm{O}_{4}$ & 370 & 74.0 & 25 & N/A & NF & {$[100]$} \\
\hline $\mathrm{Co}-\mathrm{MOF} / \mathrm{H}_{2}$ & 312 & 89.7 & 40 & N/A & NF & [101] \\
\hline $\mathrm{CC} @ \mathrm{NiCO}_{2} \mathrm{O}_{4}$ & 340 & 72 & 20 & 0.60 & $\mathrm{CC}$ & [102] \\
\hline $\mathrm{Fe}_{1} \mathrm{Co}_{3} / \mathrm{V}_{0}-800$ & 260 & 53 & 15 & $\mathrm{~N} / \mathrm{A}$ & $\mathrm{CC}$ & [103] \\
\hline $\begin{array}{c}\mathrm{NiCo} / \mathrm{Fe}_{3} \mathrm{O}_{4} / \mathrm{MOF}- \\
74\end{array}$ & 238 & 29 & 36 & 0.76 & GCE & [104] \\
\hline $\mathrm{FeNi}_{3}-\mathrm{Fe}_{3} \mathrm{O}_{4}$ & 234 & 37 & 20 & 0.28 & GCE & [105] \\
\hline NPs/MOF-CNT & & & & & & \\
\hline Ni-BDC@NiS (12h) & $330 @ 20 \mathrm{~mA} \mathrm{~cm}{ }^{-2}$ & 62 & 12 & 0.20 & Ni foil & [106] \\
\hline $\begin{array}{c}\mathrm{Ni}-\mathrm{Ni}_{3} \mathrm{~S}_{2} @ \text { Carbon } \\
\text { Nanoplates }\end{array}$ & 284.7 & 56 & 8 & 0.20 & GCE & [107] \\
\hline CogS $S_{8} @ T D C-900$ & 330 & 86 & 7 & $\mathrm{~N} / \mathrm{A}$ & GCE & [108] \\
\hline Ni-Co-S HPNA & 270 & 74 & 24 & N/A & $\mathrm{CC}$ & [109] \\
\hline Co-P@/NC-800 & 370 & 79 & 12 & 0.28 & GCE & [110] \\
\hline CoP-NS/C & 292 & 64 & 24 & 0.14 & GCE & [111] \\
\hline HP-CoP NA/NF & 258 & 91.7 & 12 & $N / A$ & NF & {$[112]$} \\
\hline $\mathrm{Co}_{0.7} \mathrm{Fe}_{0.3} \mathrm{P} / \mathrm{C}$ & 270 & 27 & $\mathrm{~N} / \mathrm{A}$ & 0.40 & GCE & [113] \\
\hline $\begin{array}{c}\text { CoNi } \\
\text { hydroxide UNSs }\end{array}$ & 324 & 33 & 2.8 & 0.20 & GCE & [114] \\
\hline $\mathrm{FeCO}_{0.5} \mathrm{Ni}_{0.5}-\mathrm{LDH}$ & 248 & 38 & 50 & $\mathrm{~N} / \mathrm{A}$ & Cu foil & [115] \\
\hline
\end{tabular}

\section{$450 \quad 4.1$ Metals/alloys}

451 Metal/alloy nanostructures can be synthesized from 2D MOF precursors at high temperature (> $452600{ }^{\circ} \mathrm{C}$ ) and inert atmosphere. The metal/alloy nanostructure and carbonaceous components 453 generated, originating from the metal units and organic ligands in the 2D MOFs, respectively, 454 ensure high conductivity and active site concentration for OER. ${ }^{[91-95]}$ Metal nanoparticles (e. g Ni 455 or $\mathrm{Co}$ ) embedded in carbon components with different compositions and morphologies derived 456 from 2D MOFs are of special interest. Xu and associates ${ }^{[91]}$ synthesized Ni nanoparticles (Ni NPs) 457 locked in few-layered nitrogen-doped graphene (Ni@NC) obtained by high-temperature 
458 annealing of Ni MOFs in nitrogen atmosphere (Figure 6a). SEM and TEM demonstrated a 459 hierarchical structure of the Ni MOFs comprising aggregated 2D nanosheets with a lateral size of 460 500-800 nm (Figure 6b and c). The carbonized product (Ni@NC) displayed a spheroidal 461 nanostructure (diameters: 20-30 nm, Figure $6 \mathrm{~d}$ and e). TEM and HRTEM further revealed that 462 the spheres were composed of Ni nanoparticle cores and 3-5 layers graphene shells (Figure $6 f$ 463 and g). Ni@NC exhibited a low $\eta$ of $280 \mathrm{mV}$ at $10 \mathrm{~mA} \mathrm{~cm}{ }^{-2}$ and excellent catalytic stability 464 (duration of $10 \mathrm{~h}$ at $1.52 \mathrm{~V}$ vs. RHE) for OER (Figure $6 \mathrm{~h}$ and $\mathrm{i}$ ). Liu and associates ${ }^{\text {[92] }}$ designed a 465 novel approach to prepare distorted hexagonal $(3,4)$-connected $\mathrm{Ni}_{2}(\mathrm{BDC})_{2}$ (DABCO) $(B D C=1,4$ 466 benzenedicarboxylic acid, DABCO = 1,4-diazabicyclo[2.2.2]octane) framework nanoplates, which 467 were transformed to $\mathrm{Ni@N-doped} \mathrm{carbon} \mathrm{nanoplates} \mathrm{by} \mathrm{pyrolysis,} \mathrm{exhibiting} \mathrm{a} \eta$ of $307 \mathrm{mV}$ at 10 $468 \mathrm{~mA} \mathrm{~cm}^{-2}$. Meanwhile, Dong and associates ${ }^{[93]}$ reported 2D carbon framework-encapsulated highly 469 dispersed Co nanoparticles from which N-doped carbon nanotubes grew (Co-NCS@CNTs) by 470 carbonizing 2D ZIF (ZIF-L) nanosheets in an atmosphere of $\mathrm{H}_{2}$ and Ar. The prepared Co471 NCS@CNTs exhibited OER catalytic activity with a $\eta$ of 360 mV at 10 mA cm². Similar Co@N472 carbon nanosheets ${ }^{[94]}$ were also synthesized, showing a $\eta$ of $400 \mathrm{mV}$ at $10 \mathrm{~mA} \mathrm{~cm}^{-2}$. 2D MOF473 derived alloy nanoparticles including carbon components have been also explored for OER 474 electrocatalysis. Alloys can provide additional synergetic effects between the metal components 475 and tenability of the electronic structure for enhanced OER performance. ${ }^{[116,117]}$ Gao and 476 associates ${ }^{[95]}$ prepared FeNi alloy nanoparticles incorporated in carbon nanoflowers (FeNi@CNFs) 477 using 2D bimetallic nanosheet-assembled nanoflower-like MOFs as precursors. The optimized 478 FeNi@CNFs showed a $\eta$ of 356 mV at 10 mA cm${ }^{-2}$, benefiting from the aligned nanosheets and 479 complex nanoflower morphology for rich active sites and fast electron transfer. Synthetic 2D 480 MOFs derived metal/alloy nanostructures can thus be formed by reduction of the metal units of 481 the 2D MOFs with the organic linker as the reducing agents at high temperature. Most current 482 related catalysts exhibit relatively weak catalytic stability (Table 3). New strategies are needed to 483 explore for robust OER electrocatalysts. 

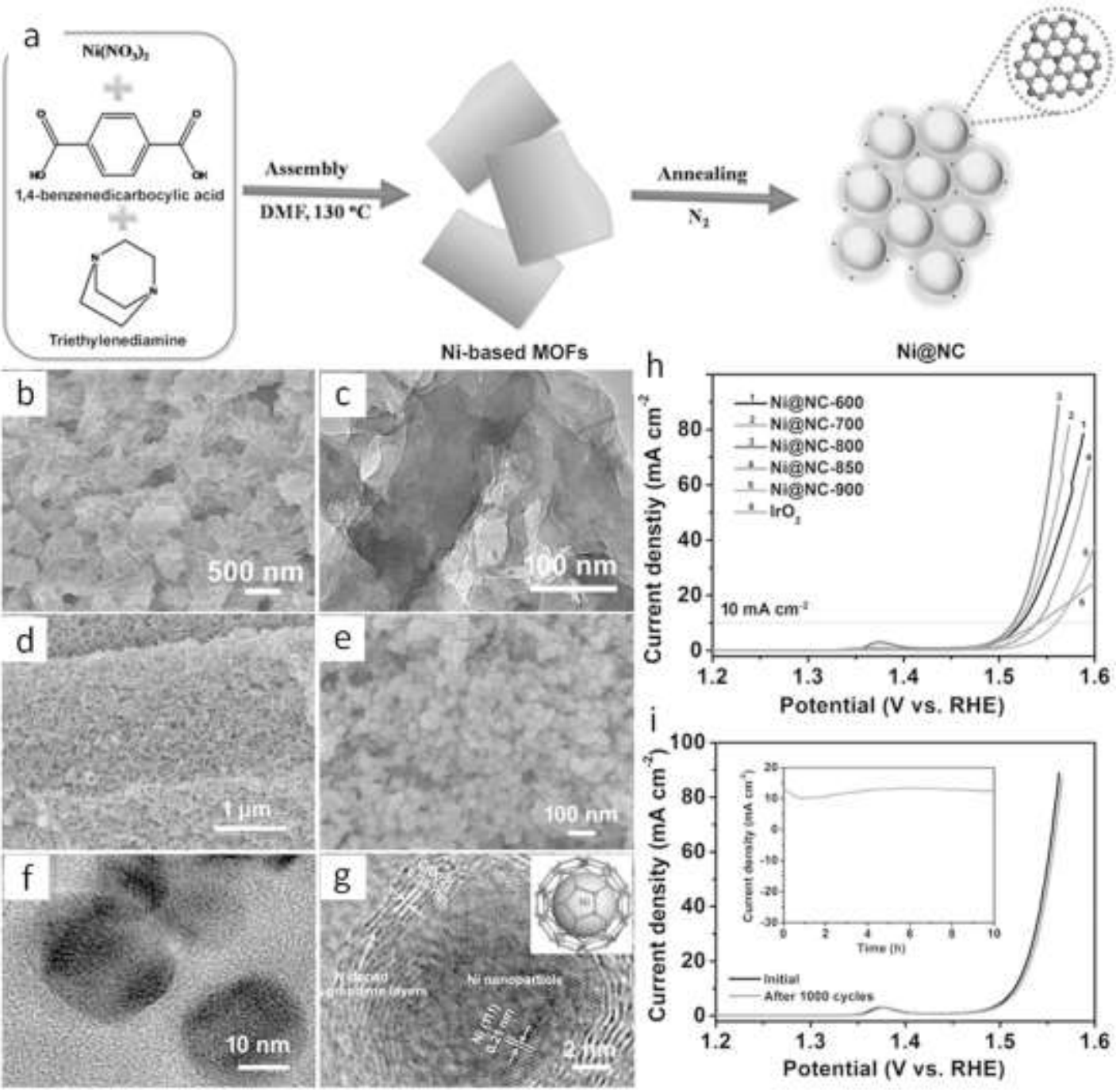

485 Figure 6. a) Schematic illustration of the preparation of Ni@NC materials from Ni-based MOF precursors. b) SEM and c) TEM images of the Ni-based MOFs. $d$ and e) SEM, f) TEM, and g) HRTEM

487 images of Ni@NC-800. The inset of $(\mathrm{g})$ is a schematic illustration of the Ni@NC structure. h) The 488 OER polarization curves of various Ni@NC samples and commercial $\mathrm{IrO}_{2}$ catalyst in $1.0 \mathrm{M} \mathrm{KOH}$ 489 solution. i) Polarization curves before and after 1000 potential cycles of Ni@NC-800. The inset of 490 (i) is the chronoamperometric curve at $1.52 \mathrm{~V}$ vs. RHE for $10 \mathrm{~h}$. Reprinted with permission from 491 Ref. ${ }^{[91]}$. Copyright (2017) WILEY-VCH Verlag GmbH \& Co. KGaA, Weinheim.

\section{$492 \quad 4.2$ Metal oxides/chalcogenides}

493 2D MOF-derived metal oxides can be prepared with morphologies and structures from the 2D 494 MOF precursors maintained, because only relatively low annealing temperatures $\left(200-600{ }^{\circ} \mathrm{C}\right)$ 
are needed. The derived carbon components can serve as conductive and protective frameworks by enclosing the metal oxides formed from the metal sites of the 2D MOFs. ${ }^{[48,90]} 2 \mathrm{D}$ MOF-derived metal oxides, such as $\mathrm{NiO}^{[96,97]}, \mathrm{CO}_{3} \mathrm{O}_{4}{ }^{[97-100]}$ and hybrid metal oxides encapsulated in carbon nanostructures ${ }^{[101-105]}$, are attracting growing attention. For instance, He and associates ${ }^{[96]}$ fabricated ultrafine NiO nanoparticles (NPs) within ultrathin 2D Ni MOFs by partial heating decomposition. Benefiting from the ultrathin 2D nanosheet-like structure and highly active sites from the defect-rich NiO NPs, the optimized Ni-MOF-250 demonstrated excellent OER catalytic performance with a $\eta$ of $250 \mathrm{mV}$ at $50 \mathrm{~mA} \mathrm{~cm}^{-2}$, achieving an industrially relevant current density of $1000 \mathrm{~mA} \mathrm{~cm}^{-2}$ at a small $\eta$ of $410 \mathrm{mV}$. Besides, Li and co-workers ${ }^{[97]}$ prepared 2D $\mathrm{Co}_{3} \mathrm{O}_{4} / \mathrm{C}_{\mathrm{BDC}}$ composites on $\mathrm{Ni}$ foil by annealing, exhibiting a $\eta$ of $208 \mathrm{mV}$ at $10 \mathrm{~mA} \mathrm{~cm}{ }^{-2}$. This was attributed to the improved conductivity and more exposed active sites offered by the 2D structure with rich hierarchical pores of the derived carbon.

2D MOF-derived bimetallic or trimetallic oxides are believed to have unique hetero-structures and modulated electronic structure, thus leading to better OER catalytic performance than single metal oxide-based electrocatalysts. Zhou and associates ${ }^{[103]}$ performed plasma-enabled Fe doping in 2D Co MOF nanosheets with considerable oxygen vacancies ( $\left.V_{0}\right)$, which were carbonized into triangular-shaped "cheese-like" Fe/Co-carbon nanosheets. The optimized $\mathrm{Fe}_{1} \mathrm{CO}_{3} / \mathrm{V}_{\mathrm{O}}-800$ exhibited a good OER performance with a $\eta$ of $260 \mathrm{mV}$ at $10 \mathrm{~mA} \mathrm{~cm}{ }^{-2}$. The authors claimed that filling the oxygen vacancies with Fe heteroatoms helped to achieve the unique heterostructure for fast electron transfer. Li and associates ${ }^{[104]}$ reported a controlled partial pyrolysis of trimetallic NiCoFe-MOF-74 in nitrogen atmosphere at $400{ }^{\circ} \mathrm{C}$ for 60 min to prepare robust $\mathrm{NiCo} / \mathrm{Fe}_{3} \mathrm{O}_{4}$ heteroparticles within 2D MOF-74 (Figure 7a). STEM imaging of NiCoFe-MOF74 (Figure 7b) showed a nanosheet-like structure. Numerous uniform nanoparticles were formed in the 2D MOFs structure after carbonization (Figure 7c). High-resolution STEM images and corresponding STEM-EELS elemental mapping of $\mathrm{NiCo} / \mathrm{Fe}_{3} \mathrm{O}_{4}$ nanoparticles (Figure $7 \mathrm{~d}-\mathrm{h}$ ) indicated the presence of metallic NiCo alloy cores with thin $\mathrm{Fe}_{3} \mathrm{O}_{4}$ shells. The as-prepared $\mathrm{NiCo} / \mathrm{Fe}_{3} \mathrm{O}_{4} / \mathrm{MOF}-74$ delivered remarkable OER performance (Figure 7i-j) with a $\eta$ as low as 238 $\mathrm{mV}$ at $10 \mathrm{~mA} \mathrm{~cm}^{-2}$ and catalytic stability of $36 \mathrm{~h}$. DFT calculations revealed the PDS of pure $\mathrm{Fe}_{3} \mathrm{O}_{4}$ was the escape of the $\mathrm{O}_{2}$ product with an energy barrier of $1.56 \mathrm{eV}$, while the PDS was the 
524 formation of ${ }^{*} \mathrm{O}$ on the $\mathrm{NiCo} / \mathrm{Fe}_{3} \mathrm{O}_{4}$ surface representing a slightly smaller energy barrier (1.48

$525 \mathrm{eV}$ ). These results confirm that the underlying NiCo alloy promoted the OER activity of $\mathrm{Fe}_{3} \mathrm{O}_{4}$

526 through exchanging stabilized active oxygen species. Compared with other 2D MOFs derivatives,

527 2D MOFs derived metal oxides could maintain stable crystalline structure easily in ambient

528 conditions with high catalytic activity. Meanwhile, the facile synthetic process can promote the 529 scalable production with low cost.

a
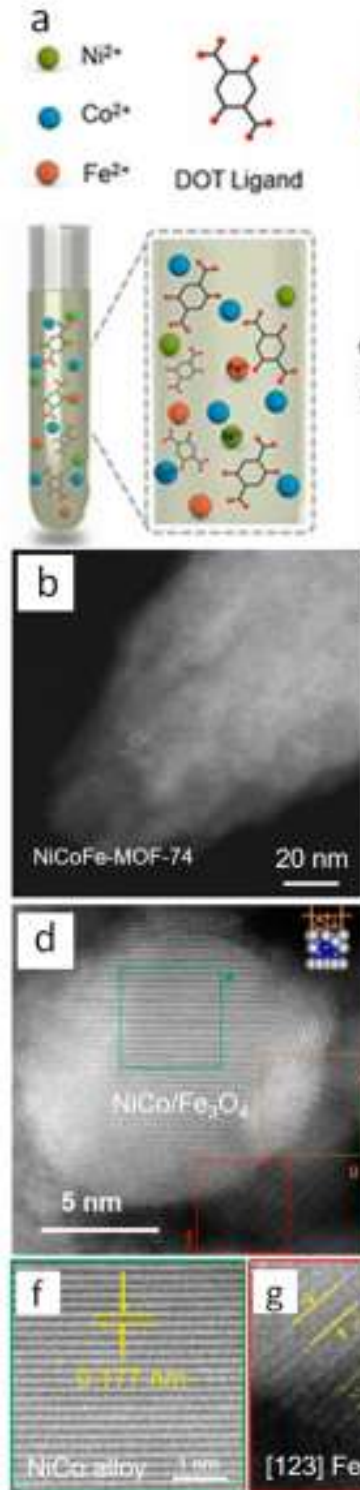
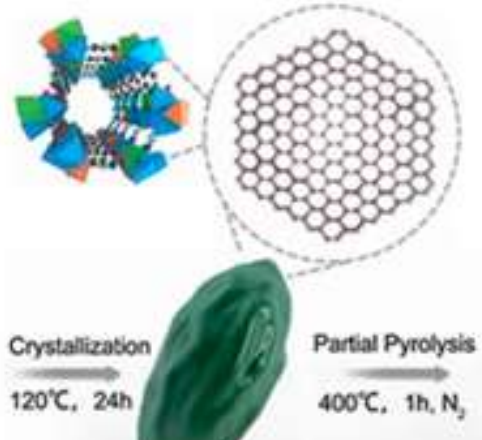

NiCoFe-MOF-74
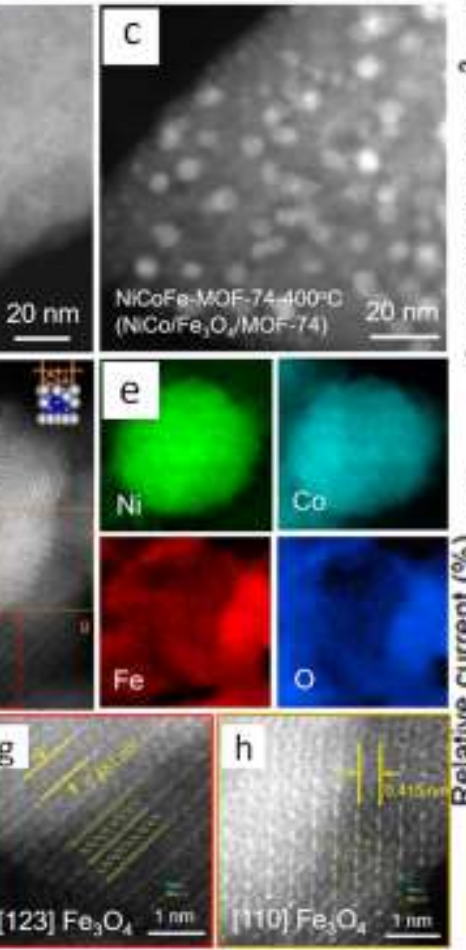
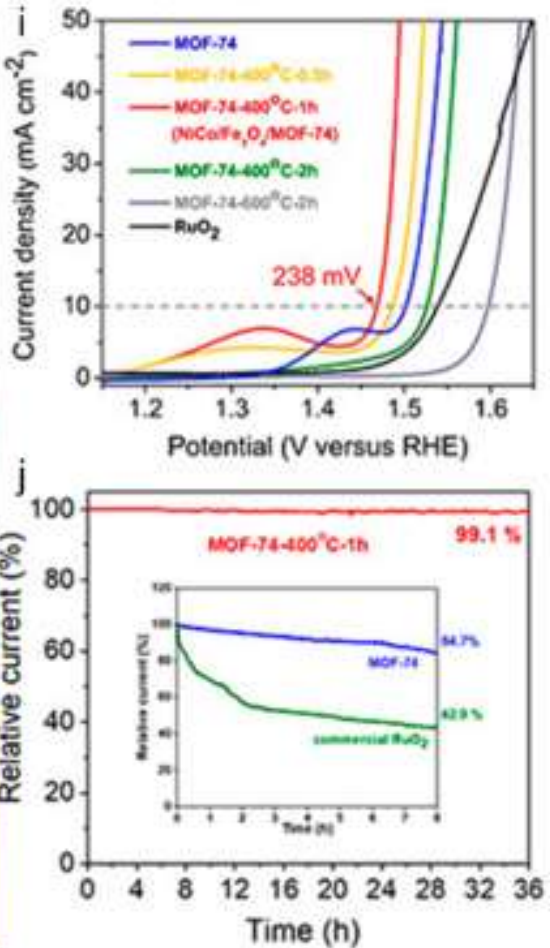

Figure 7. a) Scheme of the fabrication of trimetallic NiCoFe-MOF-74 and the partial pyrolysis of

532 NiCoFe-MOF-74 to NiCo/Fe $\mathrm{O}_{4} / \mathrm{MOF}-74$. STEM images of b) NiCoFe-MOF-74 and c) the derived

$533 \mathrm{NiCo} / \mathrm{Fe}_{3} \mathrm{O}_{4} / \mathrm{MOF}-74$ after controlled partial pyrolysis at $400{ }^{\circ} \mathrm{C}$ for $1 \mathrm{~h}$. d) High-resolution STEM 
534 image of $\mathrm{NiCo} / \mathrm{Fe}_{3} \mathrm{O}_{4}$ nanoparticle and (e) corresponding STEM-EELS elemental mappings of $535 \mathrm{NiCo} / \mathrm{Fe}_{3} \mathrm{O}_{4}$ showing the hierarchical elemental distributions of $\mathrm{Ni}, \mathrm{Co}$, and $\mathrm{Fe}$. $\mathrm{f}-\mathrm{h}$ ) Enlarged high536 resolution STEM images taken from the areas highlighted in d), with simulated atomic models 537 overlapped on the images. i) OER polarization curves of NiCoFe-MOF-74 and the derived partial 538 and completely pyrolyzed samples at $1600 \mathrm{rpm}$ in $\mathrm{O}_{2}$ saturated $1.0 \mathrm{M} \mathrm{KOH}$. j) Relative 539 chronoamperometric test under a constant potential of $1.47 \mathrm{~V}$. Reprinted with permission from 540 Ref. ${ }^{[104]}$. Copyright (2018) American Chemical Society.

541 Similar to the features of 2D MOF-derived metal oxides for OER electrocatalysis, 2D MOF-derived 542 metal chalcogenides ( $\mathrm{Ni}$-, $\mathrm{Co}-$ or NiCo-based) are also explored as oxygen evolution 543 electrocatalysts. ${ }^{[106-109]}$ The MOF-derived transition metal chalcogenides have a tunable metal544 sulfur coordination environment and good electrical conductivity for OER. ${ }^{[118]}$ For example, Li et 545 al. ${ }^{[106]}$ developed a liquid-state partial sulfurization procedure to prepare Ni-BDC@NiS catalysts. 546 The 2D $\left[\mathrm{Ni}_{3}(\mathrm{OH})_{2}(1,4-\mathrm{BDC})_{2}-\left(\mathrm{H}_{2} \mathrm{O}\right)_{4}\right] \cdot 2 \mathrm{H}_{2} \mathrm{O}(\mathrm{Ni}-\mathrm{BDC} ; 1,4-\mathrm{BDC}=1,4$-benzenedicarboxylate) MOF 547 was in-situ grown on the surface of Ni foil, which was then immersed in a thioacetamide (TAA) 548 solution for sulfurization at different durations. The optimal Ni-BDC@NiS (12 h sulfurization 549 treatment), with ordered Ni-BDC nanosheets for more accessible active sites and efficient mass 550 transfer, demonstrated a $\eta$ of $330 \mathrm{mV}$ at $10 \mathrm{~mA} \mathrm{~cm}{ }^{-2}$. In comparison to liquid-state partial 551 sulfurization, solid-state sulfurization is better controllable and the generated carbon species 552 could further enhance the electrical conductivity and improve the structural stability during the

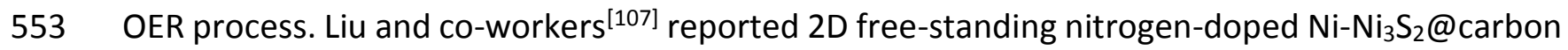
554 nanoplates by annealing $\mathrm{NiSO}_{4}$ based MOF nanoplates as the precursor through a "self555 sulfidation" procedure in an inert atmosphere. The resulting nanoplates were constructed by Ni$556 \mathrm{Ni}_{3} \mathrm{~S}_{2}$ nanoparticles homogenously embedded in a carbon matrix, exhibiting a $\eta$ of $284.7 \mathrm{mV}$ at $55710 \mathrm{~mA} \mathrm{~cm}^{-2}$ for OER. Similar self-sulfidation methods have been adopted to synthesize $\mathrm{N}, \mathrm{O}$ and 558 S-tridoped carbon matrix encapsulated with $\mathrm{Co}_{9} \mathrm{~S}_{8}$ nanocomposites (Co9 $\left.\mathrm{S}_{8} @ T D C\right)$ via direct 559 carbonization of a 2D Co MOF $\left[\mathrm{Co}(\mathrm{BDC})_{2}(\mathrm{SPDP})_{2}(\mathrm{DMF})\left(\mathrm{H}_{2} \mathrm{O}\right)\right]\left(\mathrm{H}_{2} \mathrm{BDC}\right.$ : 1,4-benzenedicarboxylic 560 acid, SPDP: 4,40-(sulfonylbis(4,1-phenylene))dipyridine, DMF: N,N-dimethylformamide). The $561 \mathrm{Co}_{9} \mathrm{~S}_{8} @ T D C$ obtained showed reasonable OER performance with a $\eta$ of $330 \mathrm{mV}$ at $10 \mathrm{~mA} \mathrm{~cm}^{-2}$. 562 Zhou and associates ${ }^{[109]}$ synthesized hierarchical porous metal sulfide (Ni-Co-S) nanosheets 
563 arrays (HPNA) directly on conductive carbon cloth (CC) substrates using 2D CoNi MOF nanosheet arrays as precursors, which underwent initial annealing and subsequent sulfurization. The

565 hierarchical porous nanostructures, affording high specific surface area, abundant active sites and short diffusion paths, ensured a better OER performance of the Ni-Co-S HPNA with a $\eta$ of 270

$567 \mathrm{mV}$ at $10 \mathrm{~mA} \mathrm{~cm}^{-2}$ than that of Co-S HPNA. Compared with 2D MOF-derived metal oxides (Table

568 3), most 2D MOF-derived metal chalcogenides electrocatalysts suffer from insufficient stability, 569 most likely due to the fact that metal chalcogenides are transformed to metal oxides to be active 570 for $\mathrm{OER},{ }^{[118,119]}$ thus suffering irreversible component and structure change in long-term 571 operation. Exploring novel hybrids to find more robust 2D MOF-derived metal chalcogenides 572 could be a possible solution. In summary, 2D MOFs derived metal oxides/chalcogenides have 573 been widely investigated as OER electrocatalysts, and much progress on the OER catalytic 574 capability and understanding of the catalytic mechanisms have been obtained over the past 575 several years.

\section{$576 \quad 4.3$ Metal phosphides/hydroxides}

577 Metal phosphides are emerging as a class of OER catalysts that display good electrical 578 conductivity and metalloid characteristics. ${ }^{[120,121]}$ The organic ligands of the 2D MOF-derived 579 carbon layers are expected to enhance the electron transfer and limit the agglomeration of metal 580 phosphide nanoparticles. Thus, 2D MOF-derived metal phosphide-carbon composites show 581 appealing OER electrocatalytic properties. ${ }^{[110-113]}$ For example, Du and associates ${ }^{[110]}$ reported the 582 synthesis of cobalt phosphide nanoparticles embedded in N-doped carbon materials (Co-P@NC) 583 using 2D Co-based porphyrin paddlewheel framework-3 (PPF-3) nanosheets as the sacrificial 584 template. The template was initially carbonized followed by low temperature phosphorization 585 using $\mathrm{NaH}_{2} \mathrm{PO}_{2}$ as the phosphor source. The Co-P@NC demonstrated a $\eta$ of $370 \mathrm{mV}$ at $10 \mathrm{~mA} \mathrm{~cm}^{-}$ 5862 for OER. Using a similar phosphorization approach, Zhu and co-workers ${ }^{[111]}$ prepared a cobalt 587 phosphide nanosheet and amorphous carbon composite (CoP-NS/C) using as-prepared 2D Co-ZIF 588 nanosheets as the template. The MOF-derived porous crystalline CoP nanosheets provided 589 highly-exposed active sites. The existence of carbon afforded fast electron transfer, ensuring the 590 good OER performance with a $\eta$ of $292 \mathrm{mV}$ at $10 \mathrm{~mA} \mathrm{~cm}{ }^{-2}$. Further, constructing metal phosphide 591 based composites on the NF substrate structure shows enhanced OER performance, due to highly 
592 exposed active sites, shortened ion diffusion path and promoted gas release during OER. Gong 593 and co-workers ${ }^{[112]}$ designed hierarchical porous CoP nanoarrays on NF (HP-CoP NA/NF) that 594 exhibited good OER electrocatalytic activity with a low $\eta$ of $258 \mathrm{mV}$ at $10 \mathrm{~mA} \mathrm{~cm} \mathrm{c}^{-2}$. A three-step 595 procedure was followed: i) Interconnected 2D cobalt-based MOFs were grown on NF via an 596 aqueous solution reaction at room temperature; ii) The MOFs were uniformly converted into 597 porous $\mathrm{CoP}$ arrays through a $\mathrm{Co}^{2+}$-etching process and iii) subsequent phosphorization. Additional 598 metal doping to the 2D MOF-derived metal phosphides is believed to modulate electronic 599 structures to lower energy barriers, resulting in bimetallic phosphides typically outperforming 600 monometallic counterparts for OER. Wang and associates ${ }^{[113]}$ fabricated $\mathrm{Co}_{1-\mathrm{x}} \mathrm{Fe}_{\mathrm{x}} \mathrm{P} / \mathrm{C}$ nanosheets 601 using 2D CoFe MOFs as precursors, retaining the well-defined 2D morphology of the MOFs. The 602 optimized $\mathrm{Co}_{0.7} \mathrm{Fe}_{0.3} \mathrm{P} / \mathrm{C}$ showed good OER catalytic performance with $\eta$ as low as $270 \mathrm{mV}$ at 10 $603 \mathrm{~mA} \mathrm{~cm}-2$. The enhanced OER performance was attributed to the 2D morphology of the carbon 604 matrix and the ultrafine character of $\mathrm{Co}_{1-x} \mathrm{Fe}_{x} \mathrm{P}$ nanoparticles. Moreover, moderate iron doping 605 preserved the catalytically active sites and improved the oxidation ability of the surfaces of the $606 \mathrm{Co}_{1-\mathrm{x}} \mathrm{Fe}_{\mathrm{x}} \mathrm{P}$ nanoparticles. Overall, 2D MOF-derived metal phosphides demonstrate relatively good 607 OER catalytic performance, but in-depth understanding of OER catalytic mechanism is still lacking. 608 More in-situ technologies and DFT simulations to study the OER active sites of 2D MOF-derived 609 metal phosphides are critically required. 


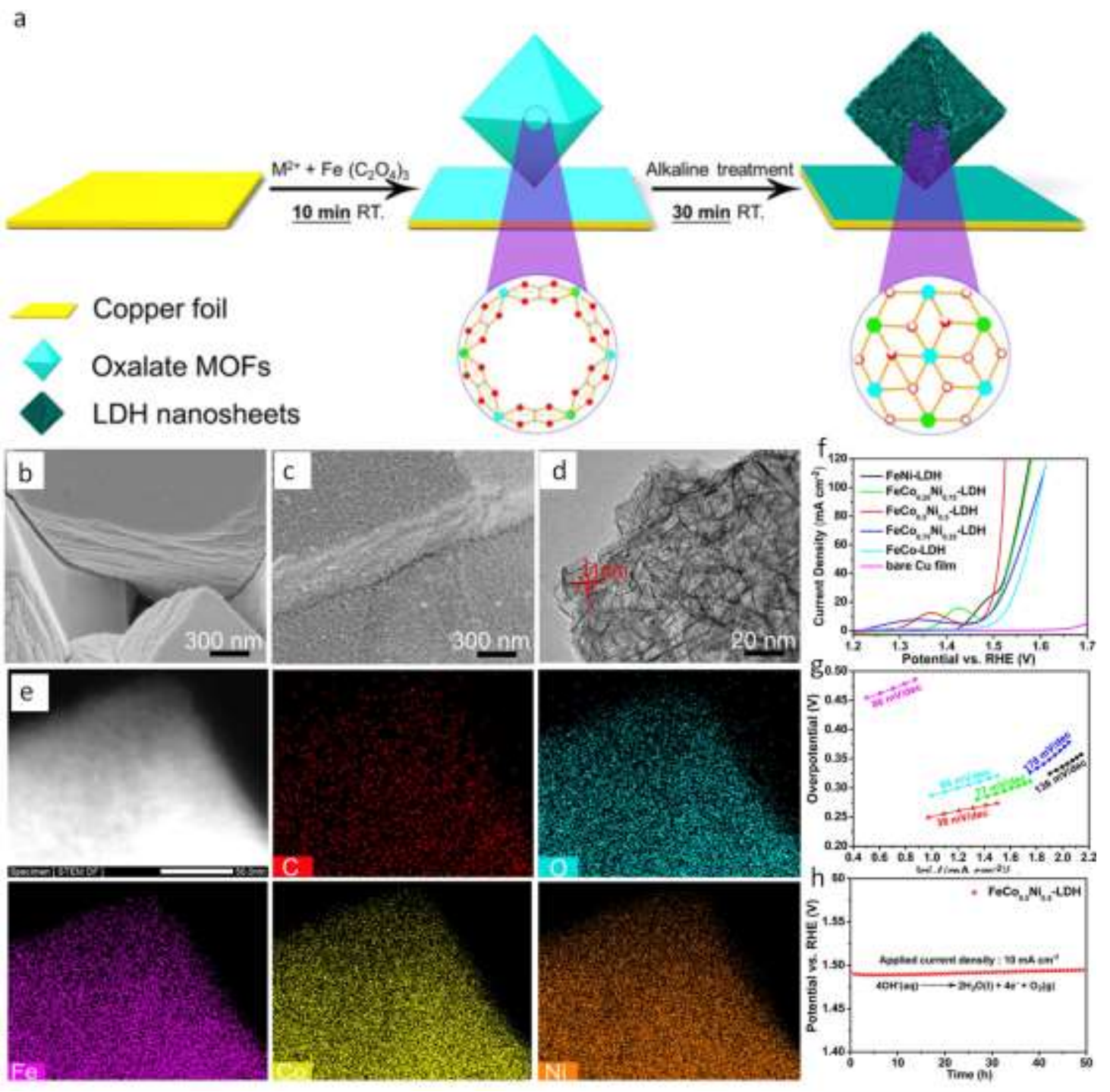

611 Figure 8. a) Schematic illustration of in-situ synthesis of layered double hydroxides (LDHs) from

612 oxalate MOFs. SEM images of (b) $\mathrm{FeCO}_{0.5} \mathrm{Ni}_{0.5}-\mathrm{MOF}$ and (c) $\mathrm{FeCO}_{0.5} \mathrm{Ni}_{0.5}$-LDH. d) HRTEM images of

$613 \mathrm{FeCO}_{0.5} \mathrm{Ni}_{0.5}$-LDH. e) STEM images of $\mathrm{FeCO}_{0.5} \mathrm{Ni}_{0.5}-\mathrm{LDH}$ and corresponding EDS mapping of $\mathrm{C}, \mathrm{O}$ and

614 Fe, Co and Ni. f) iR-corrected LSV curves and g) Tafel plots of various catalysts in $1 \mathrm{M} \mathrm{KOH}$. h)

615 Operational stability of $\mathrm{FeCO}_{0.5} \mathrm{Ni}_{0.5}-\mathrm{LDH}$. Reprinted with permission from Ref. ${ }^{[115]}$. Copyright 616 (2019) Elsevier.

617 2D MOF-derived metal hydroxides, especially layered double hydroxides (LDHs) with better ionic 618 conductivity than the conventional bulk LDHs, are attracting intensive attention for the OER. ${ }^{[114}$,

$619{ }^{115]}$ For instance, Ding and associates ${ }^{[114]}$ prepared 2D CoNi hydroxide ultrathin nanosheets (UNSs) 620 via liquid exfoliation of a CoNi MOF precursor in $0.1 \mathrm{M} \mathrm{KOH}$. The CoNi hydroxide UNSs obtained 
621 demonstrated a $\eta$ of $324 \mathrm{mV}$ at $10 \mathrm{~mA} \mathrm{~cm}^{-2}$ for OER. In addition, $\mathrm{Gu}$ and co-workers ${ }^{[115]}$ have 622 initially prepared a series of oxalate MOFs ( $\mathrm{Fe}_{x} \mathrm{Ni}_{1-\mathrm{x}}-\mathrm{MOF}$ ) grown on $\mathrm{Cu}$ foils, which were in- situ 623 transformed into LDHs in $1 \mathrm{M} \mathrm{KOH}$ for 30 min (Figure 8a). FeCo ${ }_{0.5} \mathrm{Ni}_{0.5}-\mathrm{MOF}$ (Figure 8b) showed 624 an octahedral morphology with a clearly layered structure. The derived $\mathrm{FeCO}_{0.5} \mathrm{Ni}_{0.5}-\mathrm{LDH}$ showed 625 a rougher structure (Figure $8 \mathrm{c}$ and d) composed of ultrathin hierarchical nanosheets (thickness: $6261 \mathrm{~nm}$ ). The STEM images of $\mathrm{FeCO}_{0.5} \mathrm{Ni}_{0.5}-\mathrm{LDH}$ and the corresponding EDS mapping images (Figure 627 8e) showed a uniform distribution of elemental C, O and Fe, $\mathrm{Co}$ and $\mathrm{Ni}$. The optimized FeCo ${ }_{0.5} \mathrm{Ni}_{0.5^{-}}$ $628 \mathrm{LDH}$ gave superior OER catalytic activity (Figure $8 \mathrm{f}-\mathrm{g}$ ) with a low $\eta$ of $248 \mathrm{mV}$ at $10 \mathrm{~mA} \mathrm{~cm}^{-2}, \mathrm{a}$ 629 Tafel slope of $38 \mathrm{mV} \mathrm{dec}^{-1}$ and long-term catalytic stability over $50 \mathrm{~h}$. The dynamic OER process 630 at the electrocatalyst surface was characterized by in-situ Raman spectroscopy. The Raman 631 spectra of $\mathrm{FeCO}_{0.5} \mathrm{Ni}_{0.5}$-LDH exhibited a signal at $\sim 530 \mathrm{~cm}^{-1}$ at $1.1 \mathrm{~V}$ vs. RHE (no OER), ascribed to 632 the $\mathrm{Ni}-\mathrm{O}$ stretching mode. ${ }^{[122]}$ When the potential was raised to $1.6 \mathrm{~V}$ vs. RHE (OER on-going), the 633 Raman spectra showed new peaks at $\sim 470$ and $550 \mathrm{~cm}^{-1}$, which were identified as arising from 634 the $\mathrm{NiOOH},{ }^{[123]}$ indicating that the OER active sites were $\mathrm{Ni}$ atoms. Besides, electron 635 paramagnetic resonance (EPR) spectroscopy of $\mathrm{FeCO}_{0.5} \mathrm{Ni}_{0.5}-\mathrm{LDH}$ indicated a modulating effect of 636 Co cation on the electronic structure of FeNi-LDH. In contrast to other MOFs derivatives, 2D MOF637 derived metal hydroxides have recently attracted increasing interest for OER electrocatalysis due 638 to high electrocatalytic activity and easy preparation. Hetero-components (atoms, molecules etc.) 639 can straightforwardly be incorporated in the layered host matric for tunable electronic structure 640 and enhanced OER catalytic activity, but further comprehensive studies of the OER focused on 641 the metal hydroxides are needed as noted.

642
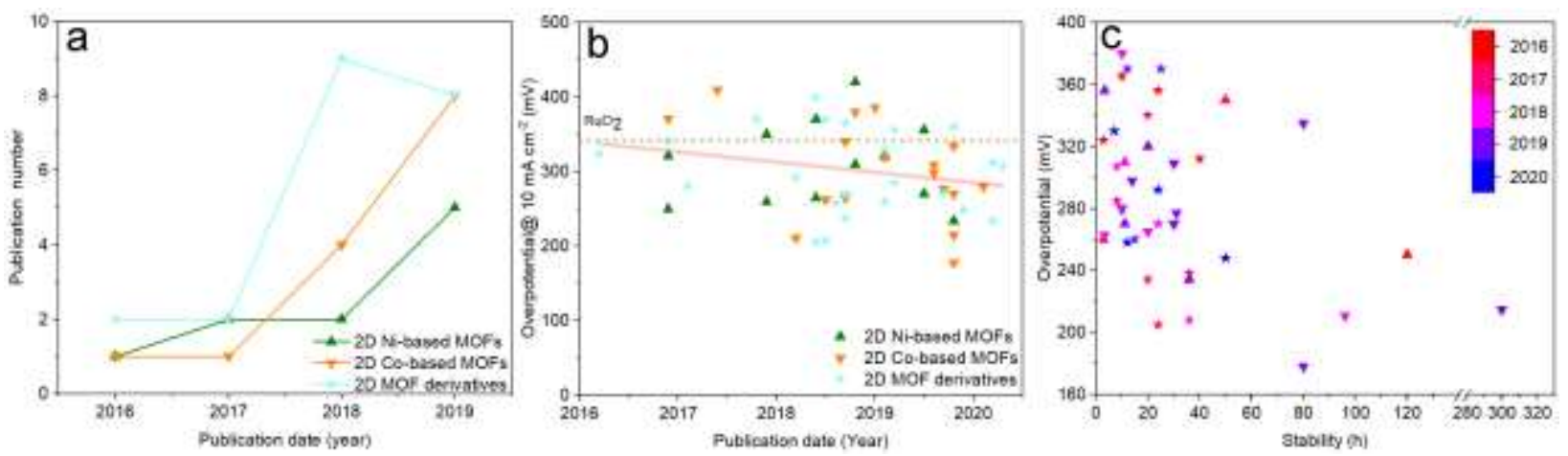
643 Figure 9. a) The number of related publications during the past years (2016-2019). Data also 644 presented in Table 1, 2 and 3. b) Chronological trend in overpotential of OER catalysts including 645 2D Ni-based MOFs, 2D Co-based MOFs and 2D MOFs derivatives in alkaline electrolytes. The grey dashed line shows the overpotential of $\mathrm{RuO}_{2}$ in alkaline electrolytes. Red line shows the

647 corresponding trend of overpotential. c) The experimental data summary between overpotential 648 and catalytic stability of 2D Ni-based MOFs, 2D Co-based MOFs and 2D MOFs derivatives in 649 alkaline electrolytes during the recent five years.

\section{5. Summarizing conclusion and perspectives}

651 We have summarized the progress in the areas of preparation, characterization, and use of 2D 652 transition metal MOFs and their derivatives as OER electrocatalysts. The number of related 653 publications keeps increasing over the past five years (Figure 9a), with the performance 654 summarized in Figure 9b-c. As shown in Figure 9b, many of these materials exhibit superior 655 catalytic activity compared to the noble-metal based catalysts such as $\mathrm{RuO}_{2}(n<300 \mathrm{mV}$ at 10 $656 \mathrm{~mA} \mathrm{~cm}^{-2}$ ), and considerable stability with only negligible decay after tens of operating hours as 657 shown in Figure $9 c$ and Table 1-3. Comparing to the evolution of other OER catalysts ${ }^{[124]}$ where 658 the overpotential dropped from around $400 \mathrm{mV}$ to $200 \mathrm{mV}$ over 7 years, the evolution of 659 performance has been similar for 2D MOFs, with no clear trend of any specific type seeming likely 660 as best leading to future improvements. Although exciting scientific achievements have been 661 reported, challenges to be overcome and new perspectives to be explored still remain in this field: 662 First, the limited stability and strong tendency of pristine 2D MOFs to agglomerate during OER 663 are limitations to their long-term applications. Despite approaches such as introduction of metal 664 ion/metal-organic components into the 2D MOFs and in-situ 2D MOF generation on NF have been 665 adopted to improve the structural stability of 2D MOFs and prevent agglomeration, more 666 efficient and facile strategies should be developed. Damage to surface morphology and pore 667 structure of 2D MOF derivatives during operation is also a critical issue, which could be addressed, 668 for example by a partial annealing method such as reported by Li et al. ${ }^{[104]}$ Second, the presently 669 reported 2D MOFs rely on expensive organic ligands and their derivatives, obtained by highly 670 energy-consuming processes, and the OER electrocatalysts obtained are mostly evaluated under 
671 alkaline solution conditions. Exploring cheap raw materials and scale-up strategies for

672 reproducible 2D MOF-based electrocatalysts with superior OER catalytic activity and high

673 stability over a wide range of $\mathrm{pH}$ values are urgently needed, especially those that can operate in

674 neutral electrolytes. Third, there are only few reports on the structural and morphological

675 evolution of 2D MOFs and their derivatives during the OER process followed by in-situ techniques

676 (e.g. in-situ XAS, Raman, TEM etc.). In comparison to ex situ characterization, in-situ techniques

677 combined with computational simulation is a powerful route to localizing the intrinsic active sites

678 and understanding the reaction mechanisms. Fourth, bifunctional electrocatalysts that are 679 capable of simultaneously catalyzing hydrogen evolution reaction and OER, or dioxygen 680 reduction reaction and OER, will hold great prospects for simplifying setups for water splitting 681 and secondary metal air batteries.

\section{$682 \quad$ Notes}

683 The authors declare no competing financial interest.

\section{Acknowledgements}

685 Financial support from Chinese Scholarship Council (201706220080), the Danish Council for 686 Independent Research for the YDUN project (DFF 4093-00297) is acknowledged.

687

\section{References}

[1] C. P. Grey, J. M. Tarascon, Nat. Mater., 2017, 16, 45-56. 
[2] X. Xiao, H.-q. Xia, R. Wu, L. Bai, L. Yan, E. Magner, S. Cosnier, E. Lojou, Z. Zhu, A. Liu, Chem. Rev., 2019, 119, 9509-9558.

[3] J. Tang, X. Yan, C. Engelbrekt, J. Ulstrup, E. Magner, X. Xiao, J. Zhang, Bioelectrochemistry, 2020, 107537.

[4] J. Ye, P. Simon, Y. Zhu, Natl. Sci. Rev., 2020, 7, 191-201.

701

[5] H. Shangguan, W. Huang, C. Engelbrekt, X. Zheng, F. Shen, X. Xiao, L. Ci, P. Si, J. Zhang, Energy Storage Mater., 2019, 18, 114-124.

[6] S. Li, M. Hua, Y. Yang, W. Huang, X. Lin, L. Ci, J. Lou, P. Si, J. Mater. Chem. A, 2019, 7, 17386-17399.

[7] W. Huang, X. Zheng, H. Shangguan, X. Xiao, J. Tang, H. Sun, K. Mølhave, L. Ci, P. Si, J. Zhang, Appl. Surf. Sci., 2020, 146513.

[9] H. Furukawa, K. E. Cordova, M. O’Keeffe, O. M. Yaghi, Science, 2013, 341, 12304441230444.

[10] B. Zhu, Z. Liang, D. Xia, R. Zou, Energy Storage Mater., 2019, 23, 757-771.

[11] Q. Hu, G. Li, Z. Han, Z. Wang, X. Huang, H. Yang, Q. Zhang, J. Liu, C. He, J. Mater. Chem. A, 2019, 7, 14380-14390.

[12] J. Kim, O. Gwon, O. Kwon, J. Mahmood, C. Kim, Y. Yang, H. Lee, J. H. Lee, H. Y. Jeong, J.-B. Baek, G. Kim, ACS Nano, 2019, 13, 5502-5512.

[13] Q. Wang, M. Nakabayashi, T. Hisatomi, S. Sun, S. Akiyama, Z. Wang, Z. Pan, X. Xiao, T. Watanabe, T. Yamada, N. Shibata, T. Takata, K. Domen, Nat. Mater., 2019, 18, 827-832.

[14] Q. Shi, S. Fu, C. Zhu, J. Song, D. Du, Y. Lin, Mater. Horiz., 2019, 6, 684-702.

[15] J. Song, C. Wei, Z.-F. Huang, C. Liu, L. Zeng, X. Wang, Z. J. Xu, Chem. Soc. Rev., 2020, 49, 2196-2214.

720 [16] I. C. Man, H. Y. Su, F. Calle-Vallejo, H. A. Hansen, J. I. Martinez, N. G. Inoglu, J. Kitchin,

[18] Q. Shi, C. Zhu, D. Du, Y. Lin, Chem. Soc. Rev., 2019, 48, 3181-3192.

[19] W. T. Hong, M. Risch, K. A. Stoerzinger, A. Grimaud, J. Suntivich, Y. Shao-Horn, Energy Environ. Sci., 2015, 8, 1404-1427.

[20] Z. P. Wu, X. F. Lu, S. Q. Zang, X. W. D. Lou, Adv. Funct. Mater., 2020, 30, 1910274.

[21] A. Vojvodic, J. K. Nørskov, Science, 2011, 334, 1355-1356.

[22] H.-F. Wang, R. Chen, J. Feng, M. Qiao, S. Doszczeczko, Q. Zhang, A. B. Jorge, M.-M. Titirici, ChemElectroChem, 2018, 5, 1786-1804.

[23] M. T. M. Koper, J. Electroanal. Chem., 2011, 660, 254-260.

[24] A. M. Kuznetsov, J. Ulstrup, Electron transfer in chemistry and biology: An introduction to the theory, John Wiley \& Sons Ltd, Chichester, UK, 1999.

[25] H. Wu, T. Yang, Y. Du, L. Shen, G. W. Ho, Adv. Mater., 2018, 30, 1804341.

[26] F. Song, L. Bai, A. Moysiadou, S. Lee, C. Hu, L. Liardet, X. Hu, J. Am. Chem. Soc., 2018, 140, 7748-7759.

[27] H. Li, M. Eddaoudi, M. O'Keeffe, O. M. Yaghi, Nature, 1999, 402, 276-279.

[28] J.-Y. Xue, C. Li, F.-L. Li, H.-W. Gu, P. Braunstein, J.-P. Lang, Nanoscale, 2020, 12, 48164825 .

[29] H. Li, K. Wang, Y. Sun, C. T. Lollar, J. Li, H.-C. Zhou, Mater. Today, 2018, 21, 108-121.

741

[30] M. Zhao, Y. Huang, Y. Peng, Z. Huang, Q. Ma, H. Zhang, Chem. Soc. Rev., 2018, 47, 62676295. 
[31] M. O'Keeffe, Chem. Soc. Rev., 2009, 38, 1215-1217.

[32] G. Liu, Z. Jiang, K. Cao, S. Nair, X. Cheng, J. Zhao, H. Gomaa, H. Wu, F. Pan, J. Membr.

744 Sci., 2017, 523, 185-196.

[33] G. Skorupskii, B. A. Trump, T. W. Kasel, C. M. Brown, C. H. Hendon, M. Dincă, Nat. Chem., 2020, 12, 131-136.

[34] R. Dong, P. Han, H. Arora, M. Ballabio, M. Karakus, Z. Zhang, C. Shekhar, P. Adler, P. S.

[35] H. C. Wentz, G. Skorupskii, A. B. Bonfim, J. L. Mancuso, C. H. Hendon, E. H. Oriel, G. T.

[36] K. S. Novoselov, A. K. Geim, S. V. Morozov, D. Jiang, Y. Zhang, S. V. Dubonos, I. V. Grigorieva, A. A. Firsov, Science, 2004, 306, 666-669.

[37] J. Huo, R. Ge, Y. Liu, J. Guo, L. Lu, W. Chen, C. Liu, H. Gao, H. Liu, Sustainable Mater. Technol., 2020, 24, e00161.

[38] E. G. da Silveira Firmiano, A. C. Rabelo, C. J. Dalmaschio, A. N. Pinheiro, E. C. Pereira, W. H. Schreiner, E. R. Leite, Adv. Energy Mater., 2014, 4, 1301380.

[39] B. Anasori, M. R. Lukatskaya, Y. Gogotsi, Nat. Rev. Mater., 2017, 2, 16098.

[40] C. E. Shuck, A. Sarycheva, M. Anayee, A. Levitt, Y. Zhu, S. Uzun, V. Balitskiy, V. Zahorodna, O. Gogotsi, Y. Gogotsi, Adv. Energy Mater., 2020, 22, 19012241.

[41] L. Li, Y. Yu, G. J. Ye, Q. Ge, X. Ou, H. Wu, D. Feng, X. H. Chen, Y. Zhang, Nat. Nanotechnol., 2014, 9, 372-377.

[42] S. W. Jung, S. H. Ryu, W. J. Shin, Y. Sohn, M. Huh, R. J. Koch, C. Jozwiak, E. Rotenberg, A. Bostwick, K. S. Kim, Nat. Mater., 2020, 19, 277-281.

[43] J. Li, C. Guo, C. M. Li, ChemSusChem, 2020, 13, 1047-1070.

[44] S. Zhao, Y. Wang, J. Dong, C.-T. He, H. Yin, P. An, K. Zhao, X. Zhang, C. Gao, L. Zhang, J. Lv, J. Wang, J. Zhang, A. M. Khattak, N. A. Khan, Z. Wei, J. Zhang, S. Liu, H. Zhao, Z. Tang, Nat. Energy, 2016, 1, 16184.

[45] H. Jia, Y. Yao, J. Zhao, Y. Gao, Z. Luo, P. Du, J. Mater. Chem. A, 2018, 6, 1188-1195.

[46] Y. Zhao, J. Wang, R. Pei, J. Am. Chem. Soc., 2020, 142, 10331-10336.

[47] D. Zhu, M. Qiao, J. Liu, T. Tao, C. Guo, J. Mater. Chem. A, 2020, 8, 8143-8170.

[48] K. Zhao, W. Zhu, S. Liu, X. Wei, G. Ye, Y. Su, Z. He, Nanoscale Adv., 2020, 2, 536-562.

[49] A. Mukhopadhyay, V. K. Maka, G. Savitha, J. N. Moorthy, Chem, 2018, 4, 1059-1079.

[50] C. Hermosa, B. R. Horrocks, J. I. Martínez, F. Liscio, J. Gómez-Herrero, F. Zamora, Chem. Sci., 2015, 6, 2553-2558.

[51] Y. Ding, Y.-P. Chen, X. Zhang, L. Chen, Z. Dong, H.-L. Jiang, H. Xu, H.-C. Zhou, J. Am. Chem. Soc., 2017, 139, 9136-9139.

778 [52] J. Huang, Y. Li, R. K. Huang, C. T. He, L. Gong, Q. Hu, L. Wang, Y. T. Xu, X. Y. Tian, S. 779

780

781

782

783

784

785

786

787

Y. Liu, Z.-M. Ye, F. Wang, D.-D. Zhou, W.-X. Zhang, J.-P. Zhang, Angew. Chem. Int. Ed., 2018, 57, 4632-4636.

[53] T. Rodenas, I. Luz, G. Prieto, B. Seoane, H. Miro, A. Corma, F. Kapteijn, F. X. L. i Xamena, J. Gascon, Nat. Mater., 2015, 14, 48-55.

[54] Z. W. Jiang, Y. C. Zou, T. T. Zhao, S. J. Zhen, Y. F. Li, C. Z. Huang, Angew. Chem. Int. Ed., 2020, 59, 3300-3306.

[55] X. Zhang, P. Zhang, C. Chen, J. Zhang, G. Yang, L. Zheng, J. Zhang, B. Han, Green Chem., 2019, 21, 54-58.

[56] H. Li, J. Hou, T. D. Bennett, J. Liu, Y. Zhang, J. Mater. Chem. A, 2019, 7, 5811-5818. 
788

[57] D. Zhu, M. Qiao, J. Liu, T. Tao, C. Guo, J. Mater. Chem. A, 2020.

[58] L. Huang, G. Gao, H. Zhang, J. Chen, Y. Fang, S. Dong, Nano Energy, 2020, 68, 104296. [59] O. L. Krivanek, M. F. Chisholm, V. Nicolosi, T. J. Pennycook, G. J. Corbin, N. Dellby, M. F. Murfitt, C. S. Own, Z. S. Szilagyi, M. P. Oxley, S. T. Pantelides, S. J. Pennycook, Nature, 2010, $464,571-574$.

[60] S. Song, J. Zhou, X. Su, Y. Wang, J. Li, L. Zhang, G. Xiao, C. Guan, R. Liu, S. Chen, H.-J. Lin, S. Zhang, J.-Q. Wang, Energy Environ. Sci., 2018, 11, 2945-2953.

[61] D. Voiry, M. Chhowalla, Y. Gogotsi, N. A. Kotov, Y. Li, R. M. Penner, R. E. Schaak, P. S. Weiss, ACS Nano, 2018, 12, 9635-9638.

[62] W. Pang, B. Shao, X.-Q. Tan, C. Tang, Z. Zhang, J. Huang, Nanoscale, 2020, 12, 3623-3629. [63] X. Wei, N. Li, N. Liu, Electrochim. Acta, 2019, 318, 957-965.

[64] C. P. Wang, H. Y. Liu, G. Bian, X. Gao, S. Zhao, Y. Kang, J. Zhu, X. H. Bu, Small, 2019, 15, 1906086.

[65] S. K. Konavarapu, D. Ghosh, A. Dey, D. Pradhan, K. Biradha, Chem. Eur. J., 2019, 25, 11141 11146.

[66] G. Hai, X. Jia, K. Zhang, X. Liu, Z. Wu, G. Wang, Nano Energy, 2018, 44, 345-352.

[67] Y. Hao, Q. Liu, Y. Zhou, Z. Yuan, Y. Fan, Z. Ke, C. Y. Su, G. Li, Energy Environ. Mater., 2019, 2, 18-21.

[68] B. J. Trześniewski, O. Diaz-Morales, D. A. Vermaas, A. Longo, W. Bras, M. T. M. Koper, W. A. Smith, J. Am. Chem. Soc., 2015, 137, 15112-15121.

[69] K. Rui, G. Zhao, Y. Chen, Y. Lin, Q. Zhou, J. Chen, J. Zhu, W. Sun, W. Huang, S. X. Dou, Adv. Funct. Mater., 2018, 28, 1801554.

[70] D. Zhu, J. Liu, L. Wang, Y. Du, Y. Zheng, K. Davey, S.-Z. Qiao, Nanoscale, 2019, 11, 35993605 .

[71] X. Li, D. D. Ma, C. Cao, R. Zou, Q. Xu, X. T. Wu, Q. L. Zhu, Small, 2019, 15, 1902218.

[72] H. Xu, B. Fei, G. Cai, Y. Ha, J. Liu, H. Jia, J. Zhang, M. Liu, R. Wu, Adv. Energy Mater., 2020, 10, 1902714.

[73] K. Jayaramulu, J. Masa, D. M. Morales, O. Tomanec, V. Ranc, M. Petr, P. Wilde, Y. T. Chen, R. Zboril, W. Schuhmann, R. A. Fischer, Adv. Sci., 2018, 5, 1801029.

[74] Y. Xu, B. Li, S. Zheng, P. Wu, J. Zhan, H. Xue, Q. Xu, H. Pang, J. Mater. Chem. A, 2018, 6, 22070-22076.

[75] X. Wang, H. Zhang, Z. Yang, C. Zhang, S. Liu, Ultrason. Sonochem., 2019, 59, 104714.

[76] M. Liu, W. Zheng, S. Ran, S. T. Boles, L. Y. S. Lee, Adv. Mater. Interfaces, 2018, 5, 1800849.

[77] M. Lu, Y. Li, P. He, J. Cong, D. Chen, J. Wang, Y. Wu, H. Xu, J. Gao, J. Yao, J. Solid State Chem., 2019, 272, 32-37.

[78] W. Li, W. Fang, C. Wu, K. N. Dinh, H. Ren, L. Zhao, C. Liu, Q. Yan, J. Mater. Chem. A, 2020, $8,3658-3666$.

[79] L. Zhuang, L. Ge, H. Liu, Z. Jiang, Y. Jia, Z. Li, D. Yang, R. K. Hocking, M. Li, L. Zhang, X. Wang, X. Yao, Z. Zhu, Angew. Chem. Int. Ed., 2019, 58, 13565-13572.

[80] J. Xu, X. Zhu, X. Jia, ACS Sustainable Chem. Eng., 2019, 7, 16629-16639.

[81] L. Zhao, B. Dong, S. Li, L. Zhou, L. Lai, Z. Wang, S. Zhao, M. Han, K. Gao, M. Lu, X. Xie, B. Chen, Z. Liu, X. Wang, H. Zhang, H. Li, J. Liu, H. Zhang, X. Huang, W. Huang, ACS Nano, 2017, 11, 5800-5807.

[82] Q. Zha, F. Yuan, G. Qin, Y. Ni, Inorg. Chem., 2020, 59, 1295-1305.

[83] Z. Xue, K. Liu, Q. Liu, Y. Li, M. Li, C.-Y. Su, N. Ogiwara, H. Kobayashi, H. Kitagawa, M. Liu, G. Li, Nat. Commun., 2019, 10, 5048. 
834

[84] J. Ma, B. Lu, S. Wang, W. He, X. Bai, T. Wang, X. Zhang, Y. Li, L. Zhang, J. Chen, F. Meng, Y. Fu, New J. Chem., 2020, 44, 2459-2464.

[85] J. Meng, Y. Zhou, H. Chi, K. Li, J. Wan, Z. Hu, ChemistrySelect, 2019, 4, 8661-8670.

[86] J. Cui, J. Liu, C. Wang, F. Rong, L. He, Y. Song, Z. Zhang, S. Fang, Electrochim. Acta, 2020, $334,135577$.

[87] H. Zhang, X. Liu, Y. Wu, C. Guan, A. K. Cheetham, J. Wang, Chem. Commun., 2018, 54, 5268-5288.

[88] Y. Qian, Z. Hu, X. Ge, S. Yang, Y. Peng, Z. Kang, Z. Liu, J. Y. Lee, D. Zhao, Carbon, 2017, $111,641-650$.

[89] Y. Lei, L. Wei, S. Zhai, Y. Wang, H. E. Karahan, X. Chen, Z. Zhou, C. Wang, X. Sui, Y. Chen, Mater. Chem. Front., 2018, 2, 102-111.

[90] H.-F. Wang, L. Chen, H. Pang, S. Kaskel, Q. Xu, Chem. Soc. Rev., 2020, 49, 1414-1448.

[91] Y. Xu, W. Tu, B. Zhang, S. Yin, Y. Huang, M. Kraft, R. Xu, Adv. Mater., 2017, 29, 1605957. [92] Y. Lin, H. Wan, D. Wu, G. Chen, N. Zhang, X. Liu, J. Li, Y. Cao, G. Qiu, R. Ma, J. Am. Chem. Soc., 2020, 142, 7317-7321.

[93] D. Chen, J. Yu, Z. Cui, Q. Zhang, X. Chen, J. Sui, H. Dong, L. Yu, L. Dong, Electrochim. Acta, 2020, 331, 135394.

[94] J. Cong, H. Xu, M. Lu, Y. Wu, Y. Li, P. He, J. Gao, J. Yao, S. Xu, Chem. Asian J., 2018, 13, 1485-1491.

[95] Y. Li, M. Lu, P. He, Y. Wu, J. Wang, D. Chen, H. Xu, J. Gao, J. Yao, Chem. Asian J., 2019, $14,1590-1594$.

[96] Q. Hu, X. Huang, Z. Wang, G. Li, Z. Han, H. Yang, X. Ren, Q. Zhang, J. Liu, C. He, J. Mater. Chem. A, 2020, 8, 2140-2146.

[97] J. Zhou, Y. Dou, A. Zhou, L. Shu, Y. Chen, J.-R. Li, ACS Energy Lett., 2018, 3, 1655-1661. [98] T. Rodenas, S. Beeg, I. Spanos, S. Neugebauer, F. Girgsdies, G. Algara-Siller, P. P. M. Schleker, P. Jakes, N. Pfänder, M. Willinger, M. Greiner, G. Prieto, R. Schlögl, S. Heumann, Adv. Energy Mater., 2018, 8, 1802404.

[99] Y. Li, H. Wang, Y. Li, Q. Wang, D. Li, R. Wang, B. He, Y. Gong, J. Catal., 2018, 364, 4856.

[100] G. Wei, Z. Zhou, X. Zhao, W. Zhang, C. An, ACS Appl. Mater. Interfaces, 2018, 10, 2372123730.

[101] Q. Xia, H. Liu, M. Jin, L. Lai, Y. Qiu, H. Zhai, H. Li, X. Liu, Nanoscale, 2020, 12, 89698974.

[102] C. Guan, X. Liu, W. Ren, X. Li, C. Cheng, J. Wang, Adv. Energy Mater., 2017, 7, 1602391. [103] W. Chen, Y. Zhang, G. Chen, R. Huang, Y. Zhou, Y. Wu, Y. Hu, K. K. Ostrikov, J. Mater. Chem. A, 2019, 7, 3090-3100.

[104] X. Wang, H. Xiao, A. Li, Z. Li, S. Liu, Q. Zhang, Y. Gong, L. Zheng, Y. Zhu, C. Chen, D. Wang, Q. Peng, L. Gu, X. Han, J. Li, Y. Li, J. Am. Chem. Soc., 2018, 140, 15336-15341.

[105] K. Srinivas, Y. Lu, Y. Chen, W. Zhang, D. Yang, ACS Sustainable Chem. Eng., 2020, 8, 3820-3831.

[106] P. He, Y. Xie, Y. Dou, J. Zhou, A. Zhou, X. Wei, J.-R. Li, ACS Appl. Mater. Interfaces, 2019, 11, 41595-41601.

[107] Y. Lin, G. Chen, H. Wan, F. Chen, X. Liu, R. Ma, Small, 2019, 15, 1900348.

[108] J.-Y. Zhao, R. Wang, S. Wang, Y.-R. Lv, H. Xu, S.-Q. Zang, J. Mater. Chem. A, 2019, 7, 7389-7395. 
879 [109] W. Chen, Y. Zhang, G. Chen, R. Huang, Y. Wu, Y. Zhou, Y. Hu, K. K. Ostrikov, J. Colloid 880 Interface Sci., 2020, 560, 426-435.

881 [110] M. Zhai, F. Wang, H. Du, ACS Appl. Mater. Interfaces, 2017, 9, 40171-40179.

882 [111] H. Li, F. Ke, J. Zhu, Nanomater., 2018, 8, 89.

883 [112] H. Wang, Y. Li, R. Wang, B. He, Y. Gong, Electrochim. Acta, 2018, 284, 504-512.

884 [113] M. Jiang, J. Li, X. Cai, Y. Zhao, L. Pan, Q. Cao, D. Wang, Y. Du, Nanoscale, 2018, 10, 885 19774-19780.

886 [114] K. He, Z. Cao, R. Liu, Y. Miao, H. Ma, Y. Ding, Nano Res., 2016, 9, 1856-1865. [115] W.-D. Zhang, H. Yu, T. Li, Q.-T. Hu, Y. Gong, D.-Y. Zhang, Y. Liu, Q.-T. Fu, H.-Y. Zhu, X. Yan, Appl. Catal. B-Environ., 2020, 264, 118532. [116] U. Y. Qazi, C.-Z. Yuan, N. Ullah, Y.-F. Jiang, M. Imran, A. Zeb, S.-J. Zhao, R. Javaid, A.890 W. Xu, ACS Appl. Mater. Interfaces, 2017, 9, 28627-28634.

891 [117] J. S. Kim, B. Kim, H. Kim, K. Kang, Adv. Energy Mater., 2018, 8, 1702774.

892 [118] W. Li, D. Xiong, X. Gao, L. Liu, Chem. Commun., 2019, 55, 8744-8763.

893 [119] S. Jin, ACS Energy Lett., 2017, 2, 1937-1938.

894 [120] J. Ryu, N. Jung, J. H. Jang, H.-J. Kim, S. J. Yoo, ACS Catal., 2015, 5, 4066-4074.

895 [121] G. Zhang, G. Wang, Y. Liu, H. Liu, J. Qu, J. Li, J. Am. Chem. Soc., 2016, 138, 14686-14693. 896 [122] J. Desilvestro, D. A. Corrigan, M. J. Weaver, J. Electrochem. Soc., 1988, 135, 885-892.

897 [123] M. W. Louie, A. T. Bell, J. Am. Chem. Soc., 2013, 135, 12329-12337.

898 [124] Z. W. Seh, J. Kibsgaard, C. F. Dickens, I. Chorkendorff, J. K. Nørskov, T. F. Jaramillo, 899 Science, 2017, 355, eaad4998.

900

901

902

903

904

905

906

907

908

909

910

911

912 
915 Two-dimensional (2D) metal-organic frameworks (MOFs) with transition metal based nodes 916 (e.g. $\mathrm{Ni}, \mathrm{Co}$ and $\mathrm{Cu}$ ) are emerging as oxygen evolution reaction (OER) electrocatalysts. The 917 preparation, characterization and performance of 2D MOFs and the derivatives for OER are 918 summarized and analysed, providing guidelines for further electrocatalyst development.

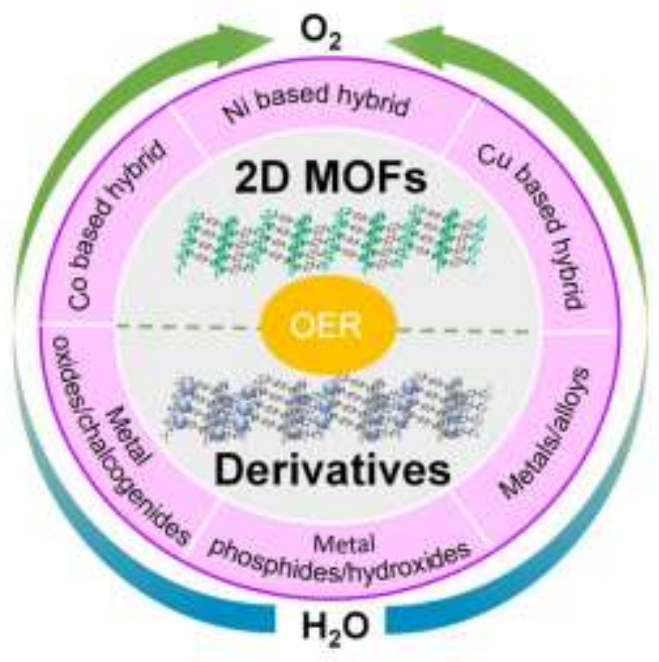

920 Mr. Wei Huang, Dr. Jing Tang, Ms. Fangyuan Diao, Dr. Christian Engelbrekt, Prof. Jens Ulstrup, 921 Dr. Xinxin Xiao and Dr. Kristian Mølhave

922 Recent progress of 2D metal-organic frameworks and their derivatives for oxygen evolution 923 electrocatalysis 